Alma Mater Studiorum - Università di Bologna DEPARTMENT OF ECONOMICS

\title{
R\&D Policy and Schumpeterian Growth: Theory and Evidence
}

Antonio Minniti

Francesco Venturini

Quaderni - Working Paper DSE N945

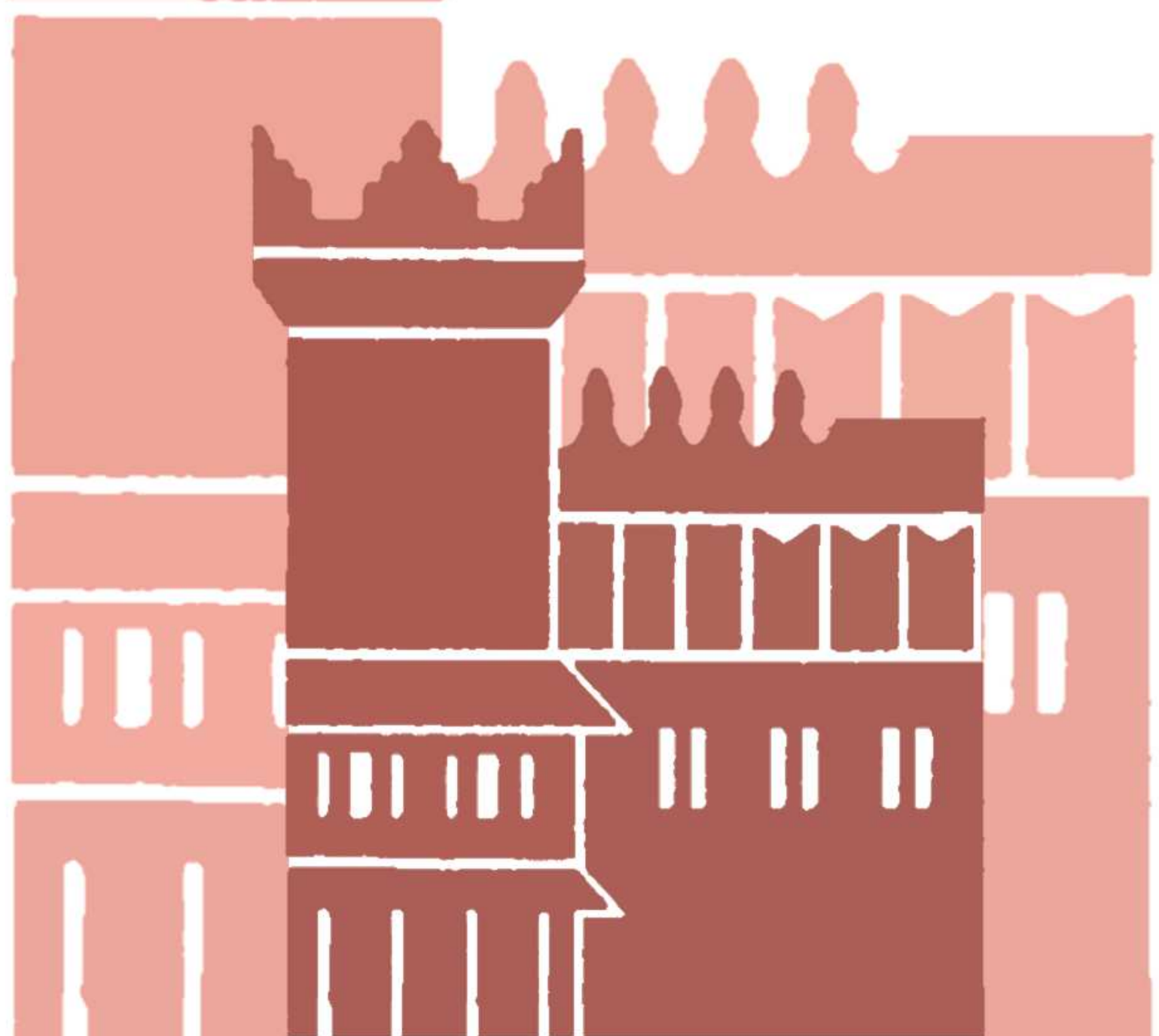




\title{
R\&D Policy and Schumpeterian Growth: Theory and Evidence
}

\author{
Antonio Minniti*
}

Francesco Venturini ${ }^{\dagger}$

May 9, 2014

\begin{abstract}
In recent years, a large body of empirical research has investigated whether the predictions of secondgeneration growth models are consistent with actual data. This strand of literature has focused on the longrun properties of these models by using productivity and innovation data but has not directly assessed the effectiveness of $R \& D$ policy in promoting innovation and economic growth. In the present paper, we fill this gap in the literature by providing a unified growth setting that is empirically tested with US manufacturing industry data. Our analysis shows that R\&D policy has a persistent, if not permanent, impact on the rate of economic growth and that the economy rapidly adjusts to policy changes. The impact of R\&D tax credits on economic growth appears to be long lasting and statistically robust. Conversely, more generous R\&D subsidies are associated with an increase in the rate of economic growth in the short run only, indicating that, at best, this policy instrument has only temporary effects. Overall, the evidence regarding the effectiveness of R\&D policy provides more support for fully endogenous growth theory than for semi-endogenous growth theory.
\end{abstract}

\section{Keywords: Schumpeterian growth theory, Innovation policy, Patenting, US manufacturing}

\section{JEL Code: O3, O38, O4}

* Department of Economics, University of Bologna, Italy. Address for editorial correspondence: Minniti Antonio, Scuola di Economia, Management e Statistica, Piazza Scaravilli n. 2, 40126, Bologna, Italy (e-mail: antonio.minniti@unibo.it, tel: +39 051 2098486 ).

${ }^{\dagger}$ Department of Economics, University of Perugia, Italy \& NIESR (e-mail: francesco.venturini@unipg.it). 


\section{Introduction}

Starting from the seminal contributions of Romer (1990), Grossman and Helpman (1993), and Aghion and Howitt (1992), a large body of theoretical literature has aimed to assess the impact of changes in public policies on aggregate outcomes on the basis of R\&D-based models of economic growth. Early models, also referred to as first-generation growth models, all exhibit a strong scale effect, namely, that the long-run rate of economic growth is proportional to the total amount of research undertaken in the economy. In these models, any change in the variables that are affected by government policies permanently influences the rate of economic growth. In the middle of the nineties, the critique formulated by Jones (1995b) regarding the predictions of first-generation growth models led scholars to rethink the foundations of R\&D-based growth theory and thus stimulated the development of a variety of second-generation growth models without scale effects 11 A first strand of subsequent research argues that economic growth is characterized by weak scale effects, in the sense that the steady-state level of per capita income is still an increasing function of the size of the economy, but not its growth rate (see, e.g., Jones 1995a; Kortum 1997; Segerstrom 1998) ? $^{2}$ Because the long-run rate of economic growth is determined by the exogenous rate of population growth, models of this type are commonly referred to as semi-endogenous growth models. In this body of research, long-run growth still reflects firms $R \& D$ choices but is independent of public policies such as investment tax credits and R\&D subsidies. The development of semi-endogenous growth theory has coincided with another line of research known as "Schumpeterian" fully-endogenous growth theory (see, e.g., Dinopoulos and Thompson 1998; Peretto 1998; Young 1998; Aghion and Howitt 2008, ch. 12) . $^{3}$ This theoretical approach shows that it is possible to eliminate the scale effect and, at the same time, to maintain that policy measures affect the rate of economic growth over the long run. This reflects a crucial difference from semi-endogenous growth theory.

A recent body of empirical research has attempted to test whether the competing predictions of secondgeneration growth models are consistent with actual data. Ha and Howitt (2007) test the two growth theories by applying cointegration analysis to US data since the fifties. The authors find strong empirical support for fullyendogenous growth theory but fail to find evidence corroborating semi-endogenous growth theory 4 To examine the ability of second-generation growth models to explain TFP growth in OECD countries, Madsen (2008) applies a similar framework of analysis, which controls for technological catch-up and international technology spillovers, to data on patents, trademarks, and R\&D expenditure. Although time-series data appear to be consistent with fully-endogenous growth theory and to provide little support for semi-endogenous growth theory, cross-country evidence indicates that no clear relationship exists between TFP growth and R\&D intensity, in contrast with

\footnotetext{
${ }^{1}$ In first-generation growth models, an increase in the scale of the economy, proxied by the number of workers in the R\&D sector, leads to a permanent increase in the rate of economic growth. Jones (1995b) criticizes this prediction by showing that the rate of total factor productivity (TFP) growth has remained constant in advanced countries despite the continued surge in R\&D expenditure.

${ }^{2}$ Semi-endogenous growth theory assumes diminishing returns to the knowledge stock and finds a less than proportional relationship between the number of researchers and economic growth. In this approach, as technology becomes more complex, rising R\&D resources are needed to maintain a given rate of TFP growth.

${ }^{3}$ Fully endogenous growth theory builds on the insight that, as an economy grows and new varieties are discovered, aggregate R\&D effort becomes less effective because it is spread among a greater number of product lines. These models retain the original assumption of constant returns to the knowledge stock and support the predictions of first-generation growth models, as a permanent increase in the fraction of $R \& D$ workers permanently influences the rate of economic growth.

${ }^{4}$ Their time-series analysis shows that the prediction of semi-endogenous growth theory, namely, that sustained TFP growth requires sustained R\&D input growth, is rejected by the data in favor of that of the Schumpeterian approach, according to which sustained TFP growth requires a sustained fraction of GDP to be spent on R\&D. Similar findings are obtained by Venturini (2012b) on the basis of industry-level data.
} 
the conclusions of previous research $5^{5}$ On the other hand, using panel data from US manufacturing industries, Venturini (2012a) estimates a set of simultaneous equation systems that model the R\&D technologies underlying the two growth theories and finds that the semi-endogenous growth model fits innovation statistics better than the fully-endogenous growth model 6

Overall, the extant literature has assessed the consistency of the two competing growth frameworks with existing data by using productivity or innovation data and, based on this evidence only, has inferred whether innovation policies have permanent or temporary effects on economic growth. However, it should be recognized that the effects of innovation policies on economic growth have not been sufficiently addressed, as most of these studies rely on a knowledge production function that, while nesting the two families of models under given parameter conditions, does not explicitly describe the role of $\mathrm{R} \& \mathrm{D}$ policy. This represents an important gap in the growth literature, particularly in the light of the debate regarding the ability of industrialized countries to restore a sustained growth process after the recent financial turmoil (see, e.g., Aghion et al., 2012).

The present paper seeks to fill this gap in the literature both theoretically and empirically. We provide a unified growth setting that yields predictions for R\&D policies, and we empirically test this growth setting by using US data. We derive a reduced-form relationship among the economic growth rate, the innovation rate, and $R \& D$ policy instruments, exploiting agents' optimality and market clearing conditions in the economy. Our theoretical setup builds on a scale-invariant R\&D growth model that is based on the quality-ladder framework developed by Grossman and Helpman (1991). We eliminate the scale effect from this model setting by assuming that the arrival of innovation in each industry negatively depends on the level of difficulty in conducting R\&D. More specifically, we consider two alternative specifications for $R \& D$ difficulty, which lead to two competing versions of the model, one for fully-endogenous growth and one for semi-endogenous growth. In the first specification, we follow Dinopoulos and Segerstrom (1999) and assume that the degree of R\&D difficulty is proportional to the market size; this assumption formalizes the notion that it is more difficult to discover a new product in a more crowded market 7 Under this formulation, growth is fully endogenous, and policy changes have permanent effects on the rate of economic growth. The second specification for R\&D difficulty has been proposed by Segerstrom (1998) and is based on the notion of diminishing technological opportunities; according to this approach, R\&D difficulty increases with the number of successful innovations in a given industry, as products become more complex. Under this formulation, growth is semi-endogenous, and policy changes have only temporary effects on the rate of economic expansion.

We test the two growth frameworks within a panel data setting by exploiting information on the US manufacturing sector over the 1975-2000 period. We study both the steady-state and the dynamic properties of these two models in order to assess whether the effects of R\&D policies are temporary (i.e., affecting output levels over the long run only), as predicted by semi-endogenous growth theory, or permanent (i.e., affecting both output levels and the rate of economic growth over the long run), as suggested by fully-endogenous growth theory. For each setup, we estimate a multi-equation system that consists of the innovation function, the R\&D difficulty equation, and the relation between the rate of economic growth and its main determinants. To allow for data persistence, we apply an autoregressive distributed lag (ARDL) approach, with lags for the dependent and independent variables

\footnotetext{
${ }^{5}$ Furthermore, it has been shown that Schumpeterian growth theory better fits the development experiences of the UK and India (Madsen et al. 2010a c), as well as the Asian growth miracle (Ang and Madsen 2011).

Madsen (2007) provides further evidence against fully-endogenous growth theory by applying panel time-series econometric techniques to data for OECD countries.

${ }^{7}$ This specification for R\&D difficulty is exploited by Dinopoulos and Segerstrom $(1999)$ to analyze the effects of trade liberalization on the wage distribution in a North-North model of scale-invariant growth. See, among others, Şener (2001) and Impullitti (2010).
} 
in each equation, and estimate the system with the seemingly unrelated regression (SUR) estimator. This step of analysis helps us to understand the entire array of forces that characterize the two growth settings. Then, we restrict the focus to the impact of $\mathrm{R} \& \mathrm{D}$ policies, and to account for heterogeneity in their short-run effects, we estimate the economic growth equation by using the pooled mean group (PMG) estimator within an error-correction mechanism (ECM) framework.

Our analysis provides useful insight into the role of innovation policies. According to our findings, R\&D policy has a persistent, if not permanent, impact on the rate of economic growth, and the economy rapidly adjusts to policy changes. However, the impact of innovation policies on economic growth varies with the type of policy instrument that is adopted. The impact of $R \& D$ tax credits on economic growth appears to be long lasting and statistically robust. Conversely, larger $R \& D$ subsidies are associated with an increase in the rate of economic growth in the short run only, indicating that, at best, this policy instrument has only temporary effects. Another valuable insight from our analysis concerns the role of $R \& D$ difficulty. Our system estimates indicate that both mechanisms of eliminating the scale effect, namely, product proliferation for fully-endogenous growth theory and diminishing technological opportunities for semi-endogenous growth theory, are empirically well founded. In fact, we show that both formulations for $R \& D$ difficulty reduce returns to $R \& D$, counteracting the contribution of $R \& D$ policy initiatives to innovation. However, taken as a whole, our evidence regarding the effects of R\&D policy lends more support to fully-endogenous growth theory than to semi-endogenous growth theory.

Our paper is also related to other important strands of economic research. First, it builds on the large body of empirical literature that, starting from the pioneering work of Zvi Griliches, uses firm- and industry-level data to assess the effectiveness of public innovation policies (see, e.g., Mamuneas and Nadiri 1996, Bloom et al. 2002). These studies focus on two major questions: (1) whether public support to perform R\&D raises, or reduces, private-sector R\&D investment (the crowding-in or crowding-out effect) and (2) whether R\&D tax credits are more effective than direct subsidies in stimulating business R\&D. Within this strand of research, our paper is more closely related to studies focusing on the impact of innovation policies on aggregate performance (see, e.g., Westmore 2013; Atkeson and Burstein 2011). Second, we also contribute to the vast body of literature on the nexus between fiscal policy and economic growth (see, e.g., Kneller et al., 1999, Arnold et al., 2011; Gemmell et al. 2011, 2013). The more recent contributions in this field have examined how tax structure changes affect the rate of economic growth over various time horizons by showing that the effects of tax structure changes on aggregate growth operate through both factor accumulation and factor productivity $]^{8}$

The rest of the paper is organized as follows. Section 2 presents the general model, while Section 3 analyses the two formulations of R\&D difficulty. Section 4 describes the empirical specifications, and Section 5 presents the data that are used in our study. Section 6 presents the results of our empirical analysis. In Section 7, we evaluate the empirical soundness of the growth mechanisms underlying the two families of models and discuss our results with reference to the existing literature. Finally, Section 8 provides conclusions.

\section{The Model}

Our theoretical setup builds on an R\&D growth model that is based on the quality-ladder framework developed by Grossman and Helpman (1991). In a multi-industry economy, firms can advance in the quality ladders of technology by investing in R\&D. Through the development of higher quality products, an innovator achieves a

\footnotetext{
${ }^{8}$ We refer to Section 7 for a thorough discussion of these bodies of research.
} 
temporary advantage and thus earns monopoly profits. To eliminate the scale effect from this growth setup, we assume that the arrival of innovation in each industry depends negatively on the rate of difficulty in conducting R\&D. More specifically, we consider two alternative specifications for R\&D difficulty. In the first specification, proposed by Dinopoulos and Segerstrom (1999), the degree of R\&D difficulty is proportional to the market size. This formulation allows for sustained per capita growth without population growth and leads to a version of the quality-ladder model in which policy changes have permanent effects on growth. This framework is also referred to as the fully-endogenous growth model. In the second specification, proposed by Segerstrom (1998), R\&D difficulty increases over time in each industry as firms conduct more R\&D. This formulation of R\&D difficulty leads to a version of the model in which the steady-state growth rate is proportional to the population growth rate and policy changes have only temporary effects on growth. For this reason, this framework is also referred to as the semi-endogenous growth model. Our model is flexible enough to nest both semi-endogenous and fully-endogenous growth within a single theoretical setup.

\subsection{Model assumptions and equilibrium conditions}

We consider an economy with a continuum of industries indexed by $\omega \in[0,1]$. Normalizing the quality of each good at time $t=0$ to one, we denote by $j_{\omega, t}$ the number of innovations achieved in industry $\omega$ by time $t$. Thus, the highest quality of good $\omega$ that can be produced at time $t$ is $\lambda^{j_{\omega, t}}$, where $\lambda>1$ represents the extent to which higher quality products improve on lower quality products. A representative household exists that is modelled as a dynastic family that grows over time at an exogenous rate, $n$. Normalizing the initial number of members of this family to one, the population size at time $t$ amounts to $L_{t}=e^{n t}$. The representative household maximizes the following lifetime utility function:

$$
U \equiv \int_{0}^{\infty} e^{-(\rho-n) t} \log u_{t} \mathrm{~d} t, \quad \text { with } \quad \log u_{t} \equiv \int_{0}^{1} \log \left[\sum_{j} \lambda^{j} d_{j, \omega, t}\right] \mathrm{d} \omega
$$

where $\rho>n$ is the subjective discount rate, $\log u_{t}$ represents the flow of utility at time $t$, and $d_{j, \omega, t}$ denotes the quantity of a product of quality $j$ produced by industry $\omega$ that is consumed at time $t$. At each point in time $t$, the household allocates expenditure to maximize $u_{t}$ for a given set of prices. Solving this optimal control problem yields a unit-elastic demand function for each product (industry) of the following type:

$$
d_{j, \omega, t}=\frac{c_{t}}{p_{j, \omega, t}}
$$

where $c_{t}$ denotes per capita consumption expenditure and $p_{j, \omega, t}$ is the quality-adjusted price 9 The intertemporal maximization problem of the representative household consists of maximizing lifetime utility $U$ under the usual budget constraint. The solution to this problem obeys the well-known Euler equation:

$$
\frac{\dot{c}_{t}}{c_{t}}=r_{t}-\rho
$$

where $r_{t}$ is the instantaneous rate of return at time $t$.

Manufacturing firms produce by using labor as a sole production factor, under a constant return to scale

\footnotetext{
${ }^{9}$ Because all products within an industry are perfect substitutes by assumption, consumers purchase only the product with the lowest quality-adjusted price.
} 
technology. One unit of labor is needed to obtain one unit of output, regardless of quality. The labor market is perfectly competitive, and labor is used as the numéraire. Thus, at each point in time, the marginal cost of production is constant and equal to the wage rate $(w=1)$. In each industry, firms compete in price. As innovations are always non-drastic, in each $\mathrm{R} \& \mathrm{D}$ race, the competition between the innovator and the incumbent leads to a limit pricing equilibrium in which the quality leader sets the price $p=\lambda$ and earns the following profits:

$$
\pi_{t}=\left(\frac{\lambda-1}{\lambda}\right) c_{t} L_{t}
$$

Any R\&D firm $i$ uses $\ell_{i}$ labor units to innovate and has an instantaneous probability $\ell_{i} /\left[b X_{\omega, t}\right]$ to succeed, where $X_{\omega, t}$ is the R\&D difficulty index and $b>0$ is a given technology parameter. Returns to R\&D investment are independently distributed across firms, across industries, and over time. Consequently, the industry-wide instantaneous probability of success in industry $\omega$ at time $t$ is simply:

$$
\iota_{\omega, t} \equiv \frac{L_{I, \omega, t}}{b X_{\omega, t}}
$$

where $L_{I, \omega, t}=\sum_{i} \ell_{i, \omega, t}$ is the industry level of $\mathrm{R} \& \mathrm{D}$ employment. Regarding the R\&D difficulty index $X_{\omega, t}$, in the next section, we will analyze two alternative specifications, which rule out explosive growth and scale effects (see Jones, 1995a).

A stock market exists that channels consumer savings to firms that engage in R\&D, helping households to diversify the risk of holding stocks issued by these firms. Since a continuum of industries exists and the probability of being a winner in an $R \& D$ race is independently distributed across firms and industries, each investor can completely neutralize its financial risk by diversifying its portfolio. The absence of any arbitrage opportunities implies that the return from holding the share of a quality leader must be the same as the return from an equally sized investment in a riskless bond. Imposing this condition yields:

$$
v_{\omega, t}=\frac{\pi_{t}}{r_{t}+\iota_{\omega, t}-\left[\dot{v}_{\omega, t} / v_{\omega, t}\right]}
$$

where $v_{\omega, t}$ denotes the expected reward for winning an $\mathrm{R} \& \mathrm{D}$ race. At each point in time, innovating firm $i$ chooses the amount of R\&D labor $\ell_{i}$ in the perspective to maximize profits $\frac{v_{\omega, t} \ell_{i}}{b X_{\omega, t}}-\ell_{i}(1-s)$, where $s$ is the fraction of $\mathrm{R} \& \mathrm{D}$ costs that are funded by the government through lump-sum taxation. The R\&D sector is characterized by a perfectly competitive environment, with free entry and a constant return to scale technology. Therefore, in any industry $\omega$ targeted by a positive and finite amount of labor to $\mathrm{R} \& \mathrm{D}$, the following condition holds:

$$
v_{\omega, t}=b X_{\omega, t}(1-s)
$$

Given the symmetric structure of the model, we focus on the equilibrium where the R\&D intensity is strictly positive and identical across industries. In the following formulations, we omit $\omega$ from the notation for the sake of brevity.

We close the model with the labor market clearing condition. In the manufacturing sector, total employment equals $c_{t} L_{t} / \lambda$, while R\&D firms hires $\iota_{t} b X_{t}$ researchers overall. Thus, the full employment condition is expressed as $1=c_{t} / \lambda+\iota_{t} b x_{t}$, where $x_{t} \equiv X_{t} / L_{t}$ is a measure of relative $\mathrm{R} \& \mathrm{D}$ difficulty. This equation defines a negative, linear relationship between per capita consumption expenditure, $c_{t}$, and the rate of innovation, $\iota_{t}$. Plugging Eqs. 
(2) and (4) into the no-arbitrage condition (3), solving for the interest rate $r_{t}$, and then substituting the resulting expression into the Euler equation (1), we easily obtain:

$$
\frac{\dot{c}_{t}}{c_{t}}=(\lambda-1) \frac{\left[1-\iota_{t} b x_{t}\right]}{b(1-s) x_{t}}-\iota_{t}+\frac{\dot{X}_{t}}{X_{t}}-\rho
$$

where we have substituted $c_{t}=\left[1-\iota_{t} b x_{t}\right] \lambda$, which is derived from the full employment condition. To conclude, we define the rate of change in consumer utility as the rate of economic growth $g$, which is obtained by substituting the consumer demand for quality leader products $d_{j, \omega, t}=e_{t} / \lambda$ into $\log u_{t}$ :

$$
\log u_{t}=\log \frac{c_{t}}{\lambda}+\int_{0}^{1} \log \lambda^{j(\omega, t)} \mathrm{d} \omega=\log \frac{c_{t}}{\lambda}+\Phi_{t} \log \lambda, s
$$

where $\Phi_{t} \equiv \int_{0}^{t} \iota_{\tau} \mathrm{d} \tau$ is the expected number of R\&D successes in the typical industry $\omega$ before time $t$. Differentiating the previous equation with respect to $t$ and then substituting $\dot{c}_{t} / c_{t}$ from Eq. (5) yields the following expression for the rate of economic growth:

$$
g=\frac{\dot{u}_{t}}{u_{t}}=\frac{\dot{c}_{t}}{c_{t}}+\iota_{t} \log \lambda=\left[\frac{\lambda-1}{b(1-s) x_{t}}-\left(\frac{\lambda-1}{1-s}+1\right) \iota_{t}+\frac{\dot{X}_{t}}{X_{t}}-\rho\right]+\iota_{t} \ln \lambda .
$$

\section{Two formulations of R\&D difficulty}

\subsection{PEG}

In the first formulation, following Dinopoulos and Segerstrom (1999), the difficulty in conducting R\&D is proportional to the market size, which is measured as total population:

$$
X_{t}=\kappa L_{t},
$$

where $\kappa>0$ is exogenously given. This specification captures the notion that it is more difficult to successfully introduce new products into a more crowded market 10 In this version of the model, policy changes produce "permanent effects on growth" (PEG).

Because relative $\mathrm{R} \& \mathrm{D}$ difficulty $x_{t} \equiv X_{t} / L_{t}=\kappa$ is constant over time, Eq. (6) is expressed as:

$$
g=\frac{\dot{u}_{t}}{u_{t}}=\frac{\dot{c}_{t}}{c_{t}}+\iota_{t} \ln \lambda=\left[\frac{\lambda-1}{b(1-s) \kappa}-\left(\frac{\lambda-1}{1-s}+1\right) \iota_{t}+n-\rho\right]+\iota_{t} \ln \lambda
$$

The model under the PEG formulation does not exhibit transitional dynamics; thus, the economy instantaneously jumps to the steady-state equilibrium. ${ }^{11}$ Setting $\dot{c}_{t} / c_{t}=0$, the square-bracket expression in g-PEG vanishes, and we obtain the steady-state growth rate:

$$
g=\iota \ln \lambda
$$

\footnotetext{
${ }^{10}$ Dinopoulos and Thompson (1996) provide microfoundations for this specification in the context of a model of growth with variety accumulation.

${ }^{11}$ As shown in Appendix A the economy instantaneously jumps to the steady-state equilibrium at time zero because any other trajectory is inconsistent with the profit-maximizing behavior of firms.
} 
with the steady-state innovation rate amounting to:

$$
\iota=\frac{\frac{\lambda-1}{b(1-s) \kappa}+n-\rho}{\frac{\lambda-1}{1-s}+1},
$$

As can be easily seen, the population growth rate, $n$, positively affects the steady-state innovation rate, $\iota$. Moreover, R\&D policy produces long-run growth effects: an increase in $s$ leads to a larger steady-state, $\iota$, which, in turn, permanently increases the rate of economic growth, $g$. The following proposition summarizes these findings.

Proposition 1. Under the PEG formulation, (i) an increase in the rate of population growth, n, permanently raises the innovation rate ( $\iota \uparrow)$, and (ii) starting from a steady-state equilibrium, an increase in the policy instrument, $s$, results in a permanent increase in the rate of innovation and economic growth ( $\uparrow, g \uparrow)$.

\subsection{TEG}

In the second formulation, following Segerstrom (1998), R\&D is initially equally difficult in all industries $\left[X_{\omega, 0}=\right.$ $X_{0}>0$ for all $\left.\omega\right]$, and R\&D difficulty increases in each industry with the cumulative R\&D effort:

$$
\frac{\dot{X}_{t}}{X_{t}}=\mu \iota_{t}
$$

where $\mu>0$ is exogenously given. This specification captures the notion that as firms conduct more $R \& D$ and $X_{t}$ increases over time, innovating becomes more difficult. In this version of the model, policy changes produce only "temporary effects on growth" (TEG).

Because $\dot{X}_{t} / X_{t}=\mu \iota_{t}$, Eq. (6) becomes:

$$
g=\frac{\dot{u}_{t}}{u_{t}}=\frac{\dot{c}_{t}}{c_{t}}+\iota_{t} \ln \lambda=\left[\frac{\lambda-1}{b(1-s) x_{t}}-\left(\frac{\lambda-1}{1-s}+1-\mu\right) \iota_{t}-\rho\right]+\iota_{t} \ln \lambda,
$$

with the dynamics of relative $\mathrm{R} \& \mathrm{D}$ difficulty $x_{t}$ given by $\dot{x}_{t} / x_{t}=\dot{X}_{t} / X_{t}-\dot{L}_{t} / L_{t}=\mu \iota_{t}-n$. In the latter equation, the term in square brackets captures the forces that affect economic growth along the adjustment path toward the equilibrium steady state, namely, relative $R \& D$ difficulty, $R \& D$ policy, and the innovation rate. This term vanishes in the steady state when the dynamic adjustment ends and the rate of economic growth is exclusively driven by its long-run determinant, $\iota .12$

In the steady state, $\dot{c}_{t} / c_{t}=0$ and $\dot{x}_{t} / x_{t}=0$. Using the latter condition, we obtain the expression for the steady-state innovation rate:

$$
\iota=n / \mu \text {. }
$$

Moreover, imposing $\dot{c}_{t} / c_{t}=0$, we find that relative $\mathrm{R} \& \mathrm{D}$ difficulty in the steady-state equilibrium amounts to:

$$
x_{t}=x=\frac{\frac{\lambda-1}{b(1-s)}}{\left(\frac{\lambda-1}{1-s}+1-\mu\right) \frac{n}{\mu}+\rho}
$$

\footnotetext{
${ }^{12}$ See Appendix $\mathrm{B}$ for an analysis of the transitional dynamics of this version of the model.
} 
Based on these results, we conclude that the steady-state growth rate is equal to:

$$
g=\iota \ln \lambda=(n / \mu) \ln \lambda
$$

As in the previous framework, it emerges that the rate of population growth $n$ positively affects the steadystate innovation rate $\iota$. In contrast to the PEG formulation, however, R\&D policy has no long-run growth effects. In fact, in the TEG formulation, any change in R\&D incentives induces a corresponding change in R\&D difficulty. R\&D difficulty neutralizes the impact of $R \& D$ policy on the rate of economic growth. As can be easily ascertained, an increase in $s$ leads to a larger steady-state $x$. Because $\dot{x}_{t} / x_{t}=\mu \iota_{t}-n, x$ can permanently increase if the innovation rate, $\iota_{t}$, temporarily overcomes its steady-state value, $\iota=n / \mu$. This, in turn, implies that the rate of economic growth temporarily exceeds the long-run steady-state rate, $g=(n / \mu) \ln \lambda$, along the adjustment path. We summarize these findings in the following proposition.

Proposition 2. Under the TEG formulation, (i) an increase in the population growth rate, $n$, leads to a higher steady-state value for the innovation rate ( $\uparrow$ ), and (ii) starting from a steady-state equilibrium, an increase in the policy instrument, $s$, results in a permanent increase in relative R\&D difficulty $(x \uparrow)$, a temporary (short-run) increase in the rate of innovation and economic growth ( $\left.\iota_{t} \uparrow, g \uparrow\right)$, and no change in the rate of innovation over the long run $(\iota=n / \mu)$.

\section{Empirical Specification}

This section describes how we empirically test the two competing growth frameworks. There is a pivotal difference between the two versions of the model concerning the role of R\&D policies in the growth process. In the PEG framework, R\&D policy affects economic growth through an increase in research levels and patenting rates. As the economy instantaneously converges to the steady-state equilibrium (i.e., there are no transitional dynamics), $R \& D$ policies exert a permanent effect on the rate of economic growth. In the TEG framework, policy instruments induce a temporary increase in innovation inputs and outcomes, as the impact of greater R\&D effort is completely neutralized by a higher level of $R \& D$ difficulty over the long term. Thus, the patenting rate remains unchanged and R\&D policies have no permanent effect on economic growth.

Our empirical strategy relies on a two-step analysis. For each growth framework, we first consider a dynamic empirical specification describing how the economy evolves and eventually approaches the steady-state equilibrium. This set-up accounts for the structural relationships of the model and is designed as a multi-equation system, which is estimated using the seemingly unrelated regression (SUR) estimator. To account for dynamics, we model each equation as an ARDL model and identify both the short- and the long-run effects of the explanatory variables. Accounting for dynamics is crucial, as the theoretical model considers some mechanisms of adjustment that, if un-controlled for, may inflate the impact of the long-run determinants of economic growth. The risk of overstating the impact of these determinants is exacerbated by the relatively short time span of the present analysis, which may not be sufficient to filter out the entire dynamics of the variables. Our empirical model admits a direct effect of R\&D policy on the rate of economic growth in both the short and the long run; in this way, we avoid the need to impose parameter restrictions that may cause a mis-specification bias and, as a result, inconsistent estimates. Our formulation is consistent with that of Westmore (2013). Overall, the system specification that we use extends the empirical model developed by Venturini (2012a) for assessing the role of innovation policy in 
economic growth. As a second step, in order to more accurately identify the permanent or transitory effects of innovation policies, we estimate an ECM specification for the economic growth equation with the pooled mean group estimator (Pesaran et al., 1999). This econometric procedure allows us to account for heterogeneity in the short-run effects of R\&D policy instruments and to measure the speed of adjustment towards the equilibrium values. Overall, this procedure guarantees consistency in the long-term (homogeneous) estimates. This part of the analysis builds upon Gemmell et al. (2011, 2013).

Overall, our empirical analysis is carried out within a panel dynamic setting with data for nineteen US manufacturing industries over the 1975-2000 period. The sample design closely reflects the sectoral nature of the background underpinning Schumpeterian growth theories. In this way, the present paper differs from most existing works, which rely upon country-level data instead. It should be acknowledged that the limited time span in this paper (25 years) may not be sufficient to understand whether the effect of R\&D policy on the long-run rate of economic growth is actually permanent or transitory; the time space is nevertheless sufficient to understand whether the effect is persistent over our study period (Gemmell et al., 2011). In what follows, we maintain the former notation.

\subsection{Dynamic system analysis}

In the dynamic structural model, we define each equation of the system as an ARDL specification. To simplify the notation, in what follows, all the equations are described as an $\operatorname{ARDL}(1,1)$ model, even though we adopt a top-down procedure based on the Akaike information criterion in the regression analysis to select the optimal number of lags for each variable.

Under the PEG formulation, the level of R\&D difficulty, $X$, is proportional to the market size, $L$. A higher $X$ renders $\mathrm{R} \& \mathrm{D}$ more difficult and requires more labor input, $L_{I}$, to achieve the same rate of innovation, $\iota$. A higher $\iota$, in turn, enhances the rate of economic growth, $g$. In contrast to the TEG framework, the PEG formulation does not include any dynamics. However, this condition may not hold empirically in the light of the time-series nature of our data. For this reason, to make the comparison between the two growth setups feasible, we also allow for a dynamic adjustment in the PEG formulation, modelling both a short- and a long-run impact for all the regressors.

Denoting industry and time by $i$ and $t$, respectively, we can express the system describing the PEG framework, consisting of Eqs. (PEG), (I-rate, and (g-PEG) as follows:

$$
\begin{aligned}
\ln X_{i t} & =\alpha_{0 i}+\alpha_{1} \ln X_{i t-1}+\alpha_{2} \ln L_{i t-1}+\alpha_{3} \ln L_{i t-2}+C D+\epsilon_{1 i t} \\
\ln \iota_{i t} & =\beta_{0 i}+\beta_{1} \ln \iota_{i t-1}+\beta_{2} \ln L_{I, i t-1}+\beta_{3} \ln L_{I, i t-2}+\beta_{4} \ln X_{i t}+\beta_{5} \ln X_{i t-1}+T_{i}+\epsilon_{2 i t} \\
g_{i t} & =\gamma_{0 i}+\gamma_{1} g_{i t-1}+\gamma_{2} \iota_{i t}+\gamma_{3} \iota_{i t-1}+\gamma_{4} s_{i t-1}+\gamma_{5} s_{i t-2}+\gamma_{6} n_{i t-1}+\gamma_{7} n_{i t-2}+C D+\epsilon_{3 i t}
\end{aligned}
$$

As in Venturini (2012a), we adopt a log-linear version of the equations expressed in levels. Below, we use the same approach for the TEG formulation. In order to control for unobserved heterogeneity, each system equation includes industry fixed effects $\left(\alpha_{0 i}, \beta_{0 i}\right.$, and $\left.\gamma_{0 i}\right)$. In Eqs. (PEG) and (g-PEG), the impact of common shocks is accounted for by a set of common time dummies $(C D)$. By contrast, the innovation equation (I-rate) includes industry-specific time trends to allow for changes in the propensity of patenting over time, $T_{i}$ (see also Zachariadis, $2003)$.

The structure of the TEG economy differs from the PEG economy in the extent to which the rate of innovation 
also acts as a determinant of R\&D difficulty growth. Moreover, the rate of economic growth in the TEG framework explicitly depends on relative R\&D difficulty, $x$, but is invariant to the proxy that is used for population growth, $n$. Formally, we have:

$$
\begin{aligned}
\ln \iota_{i t} & =\alpha_{0 i}+\alpha_{1} \ln \iota_{i t-1}+\alpha_{2} \ln L_{I, i t-1}+\alpha_{3} \ln L_{I, i t-2}+\alpha_{4} X_{i t-1}+\alpha_{5} X_{i t-2}+T_{i}+\epsilon_{1 i t} \\
d \ln X_{i t} & =\beta_{0 i}+\beta_{1} d \ln X_{i t-1}+\beta_{2} \ln \iota_{i t}+\beta_{3} \ln \iota_{i t-1}+C D+\epsilon_{2 i t} \\
g_{i t} & =\gamma_{0 i}+\gamma_{1} g_{i t-1}+\gamma_{2} \iota_{i t}+\gamma_{3} \iota_{i t-1}+\gamma_{4} s_{i t-1}+\gamma_{5} s_{i t-2}+\gamma_{6} x_{i t-1}+\gamma_{7} x_{i t-2}+C D+\epsilon_{3 i t} .
\end{aligned}
$$

In this setting, the deterministic component of each equation is consistent with the formulation that is adopted in the PEG framework. In both setups, to mitigate endogeneity issues, all the regressors are taken with one-year (or more) lags with respect to the left-hand side variables, except for the simultaneous variables of the systems ( $X$ in Eq. (8), $\iota$ and $x$ in Eq. (9) for PEG, and $\iota$ in Eq. (12) for TEG).

These multi-equation systems aim to describe the full set of mechanisms underlying the two competing growth frameworks. However, the effect of innovation policies, $s$, on economic growth represents the crucial force under assessment in this paper. The entire empirical analysis is developed considering both $R \& D$ tax credits and R\&D subsidies as policy instruments. This analysis thus represents a valuable improvement over extant empirical works based on industry- or country-level data, as most of these studies rely on one policy tool only 13

Our empirical approach has some valuable properties that make it valuable for assessing the soundness of the theoretical models and for identifying the role of R\&D policy in economic growth. First, our approach allows us to infer which forces drive the rate of economic growth over the short and long time horizons. Specifically, the short-run value of the impact of $R \& D$ policy is $\gamma_{4}+\gamma_{5}$, whereas the long-run value of the impact of $R \& D$ policy is $\left(\gamma_{4}+\gamma_{5}\right) /\left(1-\gamma_{1}\right)$. It should be stressed that the dynamic specification circumvents the risk of simultaneity bias in identifying long-run (co-integration) parameters by neutralizing the effect of short-run feedbacks. Second, the empirical specification guarantees consistency in long-run estimates regardless of the presence of both $\mathrm{I}(0)$ and I(1) variables (Pesaran et al., 1999). Furthermore, public support to R\&D can be regarded as predetermined with respect to a firm's choice to carry out innovation activities, as the decision to set fiscal incentives results from a long-lasting political process ${ }^{14}$ Finally, the panel time-series dimension of the regression is sufficiently long to neutralize the bias associated with the presence of both fixed effects and the lagged dependent variables on the right-hand side of the econometric specification (Nickell 1981).

\subsection{Heterogeneous short-run effects and long-run growth}

As the declared objective of the paper is that to identify the growth-enhancing effect of innovation policies, the second part of the analysis focuses on the economic growth equation. This part of the analysis allows us to address all possible concerns regarding our system approach. Indeed, one may be concerned about the bias associated with the simultaneous structure of the model that exacerbates mis-specification problems caused by the incomplete dynamic adjustment of the explanatory variables or heterogeneity in their effects. Using a single-equation approach helps to rule out the first issue. Another potential bias is related to the assumption of parameter homogeneity

\footnotetext{
${ }^{13}$ Exceptions in this body of literature include Mamuneas and Nadiri (1996), Westmore (2013), and Thomson (2013).

${ }^{14}$ For instance, we use the tax price component of the R\&D user cost. This measure is preferable to the full user cost of R\&D, as the latter is more pro-cyclical and more closely correlated with R\&D expenses, since it is affected by other economic variables, such as the real interest rate. Moreover, measurement errors in the R\&D user cost may be larger than those in its tax price component, and thus potentially generate an attenuation bias in the estimates (Bloom et al. 2013).
} 
across industries. Two approaches can be used to tackle this issue. The first approach consists of adopting a regression model that allows for heterogeneous parameters both in the short and the long run, such as the meangroup (MG) estimator (Pesaran and Smith, 1995). The second approach consists of restricting heterogeneity to short-run dynamics and assessing whether significant differences exist in the long-run estimates between and the first approach.

Such an assessment is done with the pooled mean group (PMG) estimator devised by Pesaran et al. (1999) which, here, is applied to the economic growth equation re-expressed in an ECM form. This regression technique allows for heterogeneous panel dynamics but imposes long-run parameter homogeneity. This procedure is more efficient than fully heterogeneous parameter estimators, such as the MG, which estimates a dynamic relationship for a single panel unit, but provides efficient and consistent estimates only when the assumption of homogeneity is violated. In the following analysis, the statistical difference between these two approaches is assessed with a standard Hausman test. Re-parametrizing Eqs. (9) and (12) as an ECM model, we work with the following two specifications: 15

$\Delta g_{i t}=\phi_{i}\left(g_{i t-1}-\gamma_{1}^{L} \iota_{i t-2}-\gamma_{2}^{L} s_{i t-2}-\gamma_{3}^{L} n_{i t-2}\right)+\sum_{r=1}^{R} \gamma_{0 i}^{S} \Delta g_{i t-r}+\sum_{j=1}^{J} \Delta \gamma_{1 i}^{S} \iota_{i t-j}+\sum_{k=1}^{K} \Delta \gamma_{2 i}^{S} s_{i t-k}+\sum_{z=1}^{Z} \Delta \gamma_{3 i}^{S} n_{i t-z}+\epsilon_{i t}$

$\Delta g_{i t}=\phi_{i}\left(g_{i t-1}-\gamma_{1}^{L} \iota_{i t-2}-\gamma_{2}^{L} s_{i t-2}-\gamma_{3}^{L} x_{i t-2}\right)+\sum_{r=1}^{R} \gamma_{0 i}^{S} \Delta g_{i t-r}+\sum_{j=1}^{J} \Delta \gamma_{1 i j}^{S} \iota_{i t-j}+\sum_{k=1}^{K} \Delta \gamma_{2 i k}^{S} s_{i t-k}+\sum_{z=1}^{Z} \Delta \gamma_{3 i z}^{S} x_{i t-z}+\epsilon_{i t}$.

Now, the short- and long-run effects of the explanatory variables are explicitly identified by the econometric model (denoted by $\gamma_{\cdot i}^{S}$ and $\gamma_{\cdot i}^{L}$, respectively). $\phi_{i}$ is the ECM term defining the percentage of the disequilibrium gap, caused by an exogenous change in the long-run values of the explanatory variables, which the economy closes in each time period. $\phi_{i}<0$ is the necessary condition to have convergence to the long-run (cointegration) equilibrium. $\phi_{i}=0$ indicates that there is no cointegration, i.e. there is no stationary relationship between the regressors on the dependent variable over the long-term horizon 16 In this part of the analysis, we pay particular attention to the adjustment parameter, as the two competing growth frameworks have opposite predictions regarding the transition to the steady-state (long-run) equilibrium. According to the PEG framework, there should be no dynamics, and the economy should instantaneously reach the long-run values. Thus, under this framework, $\phi_{i}$ should be close to the unit (in absolute terms). Conversely, under the TEG framework, the transitional dynamics is long lasting, and $\phi$ should be small and significant (in absolute terms). We elaborate on the number of years that are necessary to close the disequilibrium gap induced by an exogenous shock in the long-run values of growth drivers (in proportions of 99 and 100\%), by examining the speed of adjustment parameter $\phi_{i}$, taken as the unweighted average of individual ECM terms $17, J, K$, and $Z$ define the lag structure of the short-run effects

\footnotetext{
${ }^{15}$ The deterministic elements are omitted to save space.

${ }^{16}$ Under parameter homogeneity, the speed of adjustment coefficients for Eqs. 9 and $\left[12\right.$ are defined as $-\phi=1-\gamma_{1}$. Within the ECM framework, the condition that $\phi_{i} \in(-1,0)$ implies monotonic convergence toward the long-run target, while oscillatory (non-monotonic) trajectories of convergence would emerge when $\phi_{i} \in(-2,-1)$. The condition of stability of the adjustment process would not be satisfied if $\phi_{i} \in(-\infty,-2)$.

${ }^{17}$ The ECM specification imposes a non-linear cross-equation parameter restriction and, hence, is estimated through maximum likelihood. In addition to allowing for different short-run dynamics, this procedure can be used to estimate the long-run impact of the
} 
of the variables; nevertheless, the optimal number of lags is chosen to minimize the AIC criterion and to achieve convergence in the iterative procedure of estimation, based on maximum likelihood. As discussed above, the main advantage offered by the PMG procedure is that it provides consistent and efficient estimates for long-run coefficients under the assumption of heterogeneous dynamics. However, with relatively few time observations, the consistency of the short-run heterogeneous coefficients may not be guaranteed. For this reason, in this part of the analysis, we focus on the long-run values of the parameters, whilst for short-run values we provide a summary of the sectors in which R\&D policy instruments have positive effects and investigate why their overall impact may be zero.

\section{Data}

The regression analysis is carried out on a panel of data for nineteen US manufacturing industries over the 1975-2000 period collected from a very large set of data sources.

Innovation rate $\iota$ is defined as the ratio between the annual number of granted patents in each industry (assigned based on the application year) and their cumulative value. The cumulative value of patents is determined by adopting the perpetual inventory method and a geometric depreciation rate of $15 \%$. Each patent is weighted with the number of citations received; this quality indicator is adjusted for truncation, i.e., industry citations are scaled on the yearly manufacturing mean (Hall et al. 2001$)$. Patent data are taken from NBER Patent Data files. Research input $L_{I}$ is measured by the R\&D capital stock, constructed with the same procedure as described above, using data on $\mathrm{R} \& \mathrm{D}$ expenditure provided by the National Science Foundation 18 R\&D difficulty $X$ is defined as the maximum number of citations that are received by a patent in any single industry: the rationale is that the higher the quality of the state-of-the-art product is, the more difficult moving the innovation frontier and discovering a higher-quality product will be. Rate of economic growth $g$ is gauged by the rate of change of real value added at the industry level.

The two growth frameworks mainly differ in how R\&D difficulty is modelled and how this variable shapes innovation processes. Under the PEG formulation, $X$ is proportional to the market size, which expands because of the increasing demand for consumer product varieties (or population $L$ ). We gauge this variable with the normalized number of product types that are available in the US market (Frensch and Gaucaite Wittich, 2009):

$$
L_{i t}=\frac{\sum_{m}^{M} \sum_{c}^{C} P V_{i t-1}^{m, c}}{\sum_{m}^{M} \sum_{c}^{C} \sum_{i}^{N} \sum_{t}^{T} P V_{i t-1}^{m, c}},
$$

where $P V$ is imported varieties, $m$ denotes the five-digit product category from SITC classification $(m=1, \ldots, M)$, $c$ is the country of origin $(c=1, \ldots, C)$ (source: Feenstra et al., 2002), $N$ is the number of US industries, and $T$ is the time horizon of our analysis. This measure of product proliferation consists of the industry share of total imported varieties by the US for the period between 1975 and 200019 It reflects the product types that are demanded by domestic consumers (and firms) that a US company takes into account when it undertakes a research project directed at developing a new product. The rising demand for new varieties reduces the effectiveness of R\&D aimed at quality improvement, as research resources become thinly spread over a larger number of different

variables even when some cannot be identified for given industries because of the exact multicollinearity between their elements. In general, the PMG estimator is applicable even when the number of panel units (industries) is small.

${ }^{18}$ Unavailability of R\&D personnel data for our set of industries inhibits our ability to approximate $L_{I}$ with the number of researchers.

${ }^{19}$ This index maps the value superlative index defined by Feenstra and Kee (2007) for the product space into the production space. 
sectors. Our measure of product proliferation is preferable to those used in the literature as proxies for consumer demand or population. One of the most popular indicators that is adopted is employment; however, as discussed in $\mathrm{Ha}$ and Howitt (2007), this variable may respond less than proportionally to population growth over a short horizon of time and, hence, it may imperfectly capture the effect of product proliferation on economic growth. Consistently, within the PEG framework, we gauge $n$ with the annual rate of change of the index described in Eq. 15). By contrast, under the TEG formulation, population growth is the only source of long-run growth. In this case, we use the rate of employment growth as an industry-level proxy for $n$.

Two measures of innovation policies are used: $R \& D$ subsidies and $R \& D$ tax credit. The former is gauged by the percentage share of federally funded expenses on total $R \& D$ expenditure. The latter consists of the tax price component of the user cost of $\mathrm{R} \& \mathrm{D}$ (denoted by $\rho^{P}$ and $\rho$, respectively, below), which is inversely related to the fiscal treatment of $R \& D$ outlays. The $R \& D$ tax credit has extensively been found to promote innovation in the US manufacturing sector 20 The measure varies with the federal- $(f)$ and state-level $(l)$ fiscal discipline on $R \& D$ expenditure and corporate income through changes in the tax price component, $\rho^{P}$ (Wilson, 2009). As in Hall and Jorgenson (1967), the user cost of R\&D capital is defined as:

$$
\rho_{l t}=\frac{1-\zeta_{1}\left(k_{l t}+k_{f t}\right)-\zeta_{2}\left(\tau_{l t}+\tau_{f t}\right)}{1-\left(\tau_{l t}+\tau_{f t}\right)} \cdot\left(r_{t}+\delta\right)=\rho_{l t}^{P} \cdot\left(r_{t}+\delta\right)
$$

where $k_{t}$ denotes the effective $\mathrm{R} \& \mathrm{D}$ tax rate, $\tau_{t}$ is the effective income corporate tax rate, $\zeta_{1}$ captures the fraction of qualified R\&D expenses that are eligible for fiscal deduction, $\zeta_{2}$ is the present discounted value of tax depreciation allowances, $r_{t}$ is the real interest rate, and $\delta$ is the economic depreciation rate of R\&D capital ${ }^{21}$ The values of $r_{t}$ and $\delta$ are common across units and can therefore be neglected from the analysis. Since data on the tax price component are available at the state level, following Bloom et al. (2013), we have reattributed such values to manufacturing industries (denoted by $i$ 's) according to the spatial distribution of patent assignees (at each time $t)$ :

$$
\rho_{i t}^{P}=\sum_{l=1}^{50} \theta_{i l t-1} \cdot \rho_{l t}^{P},
$$

where $l$ indicates US states $(l=1, \ldots 50)$ and $\theta_{i l t-1}$ is the geographical share of patentees' location for industry $i$. These weights are one-year lagged with respect to tax prices to reduce possible simultaneity between innovation output and innovation policies 22

The main concern with the framework developed in Section 2 is that it identifies innovation as the sole source of economic growth. However, empirically, other important factors may drive economic growth. To avoid problems with omitted variables, we include a set of economic controls, namely, the labour share of high-skilled workers, $H S$ (source: KLEMS, 2008); the per worker value of capital stock, $K L$ (Becker and Gray, 2009); and an index of external finance dependence, FD (Von Furstenberg and Von Kalckreuth, 2006). These controls are included

\footnotetext{
${ }^{20}$ According to Mansfield (1986) and Hall (1993) among others, the Research and Experimentation Tax Credit, introduced in the Economic Recovery Tax Act (ETRA) of 1981, contributed to an increase in the R\&D expenditure of US corporations. This instrument is less affected by issues of arbitrariness and non-additionality and, often, is preferred to other policy instruments, such as R\&D subsidies (David et al. 2000 ).

${ }^{21}$ The parameter $\zeta_{1}$ is set to 0.5 , whereas $\zeta_{2}$ is set to 1 (see Wilson, 2009).

${ }^{22}$ Bloom et al. (2013, Appendix B.3.2) argue that reverse causality can be safely excluded using such data as: 1) state-level tax credits have been gradually introduced and are strongly trending up and 2) wide cross-sectional variation exists in their levels. These conditions guarantee that our state-level measure of the tax price component of R\&D capital is affected by endogeneity only to a very limited extent.
} 
into all the system equations. Moreover, we more specifically assess whether R\&D policy instruments capture some other omitted policy measures that affect economic growth. We control for the industry-level measure of the production tax burden, $T A X(\mathrm{BEA}, 2008){ }^{23}$ In addition, we allow for the growth-enhancing effect of product market liberalization by including an index of upstream deregulation, $P M C$. This index reflects the extent to which service deregulation exerts an effect on manufacturing industries' performance through interindustry transactions of intermediate inputs. $P M C$ is the complement to one of the OECD regulation impact indicator developed by Conway and Nicoletti (2006). To simplify the analysis, such policy controls are used within the equation for $g$ only $(T A X$ and $P M C){ }^{24}$

Table 1 reports summary statistics for the main variables that are used in the analysis. In the United States, the rate of innovation almost reached $16 \%$ per year. On the production side, output grew considerably slower, at about $6 \%$. On average, the endowment of knowledge stock (R\&D capital), which is used as a proxy for research input in this study, was 248 billion dollars per industry. The number of product varieties that are annually imported were abundantly greater than two thousand units. ${ }^{25}$ This value increased slowly over time $(0.2 \%$ per year), and from this perspective, the growth of this variable did not differ significantly from that of employment, which, in the TEG formulation, is the proxy that is used for $n$ ( $0.4 \%$ per year). The number of maximum (adjusted) forward cites that were annually registered in each industry was 17, with a range spanning from 3 to 117; this value increased by $1.5 \%$ between 1975 and 2000. Finally, the bottom part of the table shows the average value of $R \& D$ policy instruments. The price component of $R \& D$ tax credit amounted to 1.348; this variable was greater than the unity in all industries and over the entire time span, indicating that R\&D outlays steadily benefited from a preferential fiscal treatment with respect to standard capital assets. The amount of industry R\&D expenditure that was funded by federal agencies amounted to $12 \%$. Defense firms, grouped into the Other transport equipment sector, notably received the largest public support to perform R\&D.

\section{Empirical Results}

\subsection{Dynamic system}

We start the empirical analysis by showing the results for the system of dynamic structural equations. Tables 2 and 3 report the coefficients estimated for the two growth frameworks over the short and long time horizons, displaying the related p-values in square brackets ${ }^{26}$ Column (1) of each table reports the baseline results. Column (2) replicates this regression by adopting the real value added per worker as a measure of $Y$. In principle, this measure could be considered as another sound proxy for the industry growth performance. Nonetheless, in our setting, the scaling factor (total employment) may capture the impact of product proliferation, meaning that the rate of output growth may be deflated by the effect of variety expansion driven by demographic dynamics. Accordingly, the results should be interpreted with caution. In the subsequent regressions, we introduce economic controls into the equation system. These controls are used to capture whether the growth process differs among industries on the basis of structural features, such as the skill intensity of the workforce (HS in col. 3), the

\footnotetext{
${ }^{23} T A X$ is defined as the ratio of industry taxes on production and imports to value added.

${ }^{24}$ In the regression analysis, all the variables that are not expressed as percentage shares or rates of change are taken in logs. This particularly applies to the price component of the R\&D user cost in the economic growth equation. For this variable, the estimated parameter consists of a semi-elasticity, and therefore, in the tables of the results, this variable is divided by 100 to make it comparable to the coefficient for R\&D subsidies (which is an elasticity).

${ }^{25}$ To make the descriptive analysis meaningful, unlike in Eq. 15 , these values are not scaled.

${ }^{26}$ The statistical significance of the long-run values is computed with the delta-method.
} 
dependence on external finance ( $F D$ in col. 4), and the capital-labor ratio ( $K L$ in col. 5). Columns (6) and (7) include the average industry rate of production tax and the index of upstream competition, respectively, in order to exclude the possibility that the impact of these broad policies is misinterpreted as an effect of the R\&D instruments ${ }^{27}$ Finally, column (8) introduces R\&D capital over value added into the growth equation, in order to avoid the possibility that the impact of this variable is captured by the coefficient for $s$, and thus the possibility that the effect of $R \& D$ policy instruments is overstated. In other words, the latter variable might capture the growth effect of the knowledge base generated by $\mathrm{R} \& \mathrm{D}$ and other innovation activities that are not directly related to patenting but that are somehow influenced by innovation policies. This issue is broadly discussed in Westmore (2013).

\section{Permanent effects on growth framework}

Estimates of Eq. (7) indicate that R\&D difficulty is raised by the expanding number of product varieties that are merchandised in the US market. In the baseline regressions without control variables (cols. 1 and 2), the estimated impact of this variable is approximately 0.107 in the short run and 0.177 in the long run. The values of coefficients, as well as their statistical significance, are reduced somewhat after accounting for industry structural characteristics; however, none of these additional variables turns out to be significant (cols. 3-6) ${ }^{28}$

In our baseline regressions for Eq. (8), the rate of patenting appears to be positively influenced by research input and negatively influenced by R\&D difficulty $\left(L_{I}\right.$ and $\left.X\right)$. In column (1), the short-run coefficient for $L_{I}$ is 0.116 , with p-value of 0.013 , that for $X$ is -0.047 , with p-value of 0.010 . The impact of the former variable falls in the lower bound of the range of values that are reported for research input in earlier studies (see, among, others Bloom et al. 2013). This result also holds when the additional covariates are included in the empirical model (cols. 3-5). In col. (5), the change in the parameter size for research input may signal some misspecification problems for the innovation function equation, which likely depend on the diverging trends in capital accumulation across industries. Indeed, sectors that are intensive in physical capital are less likely to be involved in knowledge-generating activities as well as in the accumulation of intangible assets. This is indicated by the negative and significant coefficient for $K L$, which contrasts the positive coefficient obtained for $\mathrm{R} \& \mathrm{D}$ capital. In this regression, the coefficient for the R\&D capital is moderately larger than that in our previous estimates. The insignificance of the high-skilled labor share for the rate of patenting reveals that only human resources devoted to R\&D are useful for research activities; in other words, no role can be ascribed to either skilled labour devoted to informal or incremental (non-R\&D) innovation, or to those tasks that are complementary to formal research. Moreover, dependence on external finance has no effect on innovation outcomes 29 It is interesting to point out that the positive effect of research input largely dominates the detrimental impact of $R \& D$ difficulty ${ }^{30}$ This result corroborates the finding in most empirical analyses that the positive effect of the ratio between $L_{I}$ and $X$ (usually referred to as normalized R\&D input or research intensity, as in Ang and Madsen, 2011) on patenting is not due to the former variable alone but is reflected the net effect of these two forces. This finding represents a novel piece of evidence that the present

\footnotetext{
${ }^{27}$ It should be noted that higher values imply heavier tax burdens for TAX and weaker protection against competition for PMC.

${ }^{28}$ These findings are confirmed when we use an iterative procedure over the estimated disturbance covariance matrix that allows the seemingly unrelated regression estimator to converge to the maximum likelihood results. Estimates obtained by using single-equation estimators are similar in size but less efficient than those shown in the main text. Comparable estimates emerge for the TEG framework discussed below. All estimates are not reported but are available from the authors upon request.

${ }^{29}$ This result is consistent with the findings for the US reported by Venturini (2012a) but inconsistent with international economy-wide or industry-level evidence reported by Ang (2011) and Franco et al. $[2013)$, among others.

${ }^{30}$ The p-value of the Wald test for the parameter equality between $L_{I}$ and $X$ in col. (1) is 0.001 for both time horizons.
} 
work contributes to the Schumpeterian growth literature. On average, in Eq. (8), the coefficient for R\&D input is between two and three times as large as that for R\&D difficulty in the short run. However, it should be observed that the economic impact of the explanatory variables increases considerably over the long-term horizon, while the precision of the estimates slightly decreases. The long-run value of $R \& D$ input ranges from 0.349 in col. (3) to 0.462 in col. (5), and that of R\&D difficulty ranges from -0.145 to -0.109 . However, the most interesting insights come from estimating the growth equation (Eq. 9). For this set of results, our discussion focuses on the main explanatory variables, i.e., the rate of innovation and R\&D policy instruments ( $\iota$ and $s$ ), which will be the object of further investigation in Section 6.2. Table 2 shows that the patenting rate spurs the rate of economic growth, with a short-run effect ranging between 0.422 and 0.596 and a long-run effect ranging between 0.624 and 0.845 . Using the most conservative figures, a $1 \%$ increase in patenting translates into a $0.4-0.6 \%$ increase in the rate of output growth. This result is close to the overall growth effect of patent performance estimated by Zachariadis (2003) for the US manufacturing sector for an earlier period of time ${ }^{31}$ The key results of the analysis concern the role of policy instruments. The tax price component of the R\&D user cost has a significant and negative impact on output growth over both the short- and the long-term horizon, meaning that innovation policies have a direct and positive effect on economic growth that persists over time. Although the difference in the parameter for $\rho^{P}$ between the two time spans is statistically significant, the full vector of coefficients turns out to be identical in the short and long run 32 This result is consistent with another key characteristic of the PEG framework, which postulates that the economy is always placed on the steady-state growth path. This issue will be investigated in depth below. By contrast, the results in Table 2 show that R\&D subsidies do not significantly affect output growth. This result supports the view that this type of policy instruments may not be particularly effective in stimulating research engagement or raising output levels (see Mamuneas and Nadiri, 1996 and Westmore, 2013. respectively): federal funds crowd out privately funded research expenses, leaving the overall amount of $R \& D$ engagement unchanged; therefore, their net effect on economic growth is irrelevant (non-additionality; see also Guellec and Van Pottelsberghe, 2003).

Overall, the growth effect of patenting and R\&D policies is robust across specifications $(\iota$ and $s)$, as this effect is confirmed when we include either economic or policy controls. Although this finding may be explained with the lack of statistical power of such additional regressors, it should be noted that the same results are obtained when the control variables are expressed in rates of change rather than in levels (unreported for the sake of brevity) or in PMG estimates when they are found to be significant. Quantitatively, with the values of column (1) as a benchmark, our punctual estimates indicate that a unit decrease in the R\&D tax price, induced by a more generous fiscal treatment of R\&D outlays, would raise the rate of economic growth by approximately $0.05 \%$. This value is comparable in magnitude with the impact of (non-)distortionary taxes and other public fiscal variables on GDP growth found by Gemmell et al. (2011) for OECD countries. In our system regressions, the rate of product variety growth enters into Eq. (9) as a negative value. Below, it is shown that the coefficient sign of this variable is particularly unstable when the PMG estimator is used.

\footnotetext{
${ }^{31}$ Extrapolating the output growth effect of patenting from col. I, Table 2, in Zachariadis (2003), we obtain an approximate value of $0.4(=0.083 / 0.206)$.

${ }^{32}$ The p-value of the non-linear Wald test on the parameter equality for the R\&D tax price over the two time horizons is 0.025 . When we consider all the regressors together, the p-value is 0.138 .
} 


\section{Temporary effects on growth framework}

In the TEG framework, the rate of innovation is significantly driven by R\&D input and R\&D difficulty, consistent with the predictions of theory (see the estimates of Eq. 10, Table 3). In both time spans, the effect of $L_{I}$ always prevails over that of $X$. Again, the gap between these two forces is at its maximum in the specification in which the capital-labor ratio is included as a control variable. Taken in absolute terms, the size of the parameters is slightly larger than that in the PEG estimates, particularly in the long run and for the level of R\&D difficulty, $X$.

One distinctive characteristic of the semi-endogenous growth setting is that R\&D difficulty sterilizes the effect of increasing research effort (Eq. 11). The increase in the effect of R\&D difficulty over time is explained by the rate of innovation: the higher the rate of patenting is, the more difficult obtaining the next state-of-the-art product innovation will be. This theoretical mechanism seems to be empirically grounded. Interestingly, economic controls are irrelevant for the dynamics of $R \& D$ difficulty, suggesting that this variable strictly depends on technological factors. According to our estimates, a $1 \%$ increase in the rate of patenting raises the rate at which R\&D difficulty increases by almost 3\% in the short run, and $1.5 \%$ in the long run. The long-run effect is consistent with the value reported in Venturini (2012a) 33

Let us now turn to the estimates of Eq. 12. In terms of parameter size, the impact of the innovation rate is slightly higher than that found for the PEG framework, while the impact of R\&D tax credit is smaller (in absolute terms). Both variables are strongly significant in the baseline regressions (cols. 1 and 2). However, the statistical significance of the innovation rate remarkably decreases when R\&D capital (scaled on output level) is included in the regression, indicating that our proxies for innovation output and input may reflect two sides of the same coin (col. 8). On the other hand, the R\&D tax credit variable is no longer significant when our proxy for the capital intensity of production is accounted for (col. 5); again, this result cannot be considered to be definitive, as the control variable is not significant. Further notable findings are that the subsidy rate is unrelated to output growth across the various specifications and that there is no evidence of a detrimental role of relative R\&D difficulty, whose coefficient turns out to be positive but not always significant.

A crucial insight coming from the assessment of innovation policies within the semi-endogenous growth setting is that the tax price component of the R\&D user cost positively influences the rate of economic growth in both the short and the long run, with a small gap in the parameter size between the time horizons (the p-value of the Wald test on parameter equality is 0.052 in col. 1). Furthermore, the failure to reject the null hypothesis of no difference in the entire vector of coefficients corroborates the view that the effect of the explanatory variables persists over time (Wald test $\mathrm{p}$-value $=0.259$ in col. 1 ). This result clearly contradicts one key prediction of the TEG framework, as the direct impact of R\&D policies on economic growth should be observed over the shortterm horizon only (i.e., their effect is temporary). This finding may have been obtained for various reasons. First, it might reflect the large heterogeneity in the short-run effects of innovation policies, which, if not accurately controlled for, may result in a bias in the estimations of the long-run coefficients. Another plausible explanation could be related to the relatively short time horizon covered in the data, which may be unfit to completely filter out the dynamic adjustment of the variables, especially in the presence of long-lasting transitional dynamics. These sources of concern are addressed in the following section.

\footnotetext{
${ }^{33}$ The short-run estimates exceed long-run values as convergence toward the equilibrium values follows a non-monotonic pattern. It should also be noted that the efficiency of such estimates is moderately sensitive to how the overall system is specified, as indicated by the decrease in the significance of the parameter for the innovation rate when policy controls are included in Eq. 12 .
} 


\subsection{Heterogeneous dynamics and long-run growth effects of R\&D policies}

In this section, we investigate more in more detail the determinants of the rate of economic growth by using the PMG estimator. The results for the PEG framework are illustrated in Tables 4 and 5 . The former table reports the long-run parameters, which are assumed to be homogeneous across industries. The sequence of estimates is presented in a manner similar to that for the system regressions in order to facilitate the comparison. Table 5 summarizes the main findings for the short-run parameters, when the coefficients are allowed to vary across panel units. Following Gemmell et al. (2011), we quantify the number of sectors in which innovation policies are found to have positive short-run effects rather than focus on the size of parameters. We adopt this approach because cross-industry heterogeneity in estimates is very large and may be exacerbated by various forms of endogeneity (measurement errors, omitted variables, etc.). In Table 5, we also identify the industries in which our set of R\&D policy instruments have adverse effects and, more interestingly, determine the industries in which such measures compensate for each other, leaving unchanged the rate of output growth. This part of the analysis allows us to better define the timing and net effect of R\&D policies on economic growth.

The results in col. (1) of Table 4 are broadly in line with the ones of the benchmark specification for the PEG system (see Table 2). However, there are non-negligible differences in the magnitude of the coefficients, as well as in the level of significance for R\&D subsidies. These differences likely result from relaxing the assumption of homogeneous dynamics, which allows us to increase the precision of the long-run (cointegration) estimates. In all regressions, the PMG estimator provides estimates that are comparable to the Mean Group estimator in terms of consistency but preferable to the Mean Group estimator in terms of efficiency. The null hypothesis of no parameter difference between these two procedures cannot be rejected at the maximum level of significance (Hausman test $\mathrm{p}$-value $=1.00)$. In the baseline regression, the growth effect of the innovation rate is estimated to be nearly unity (0.968): any change in the rate of patenting results in a nearly equal change in the growth rate of industry output. The coefficient for the tax price component of the R\&D user cost is about one half that found in the system estimation; this result likely reflects the large cross-industry heterogeneity through which this instrument shapes firms' decisions to engage in $R \& D$ and all other related activities that improve their competitiveness and growth performance.

Relying on more precise estimates, in this section we investigate the dynamic properties of the PEG framework, examining how the US economy adjusts to the long-run equilibrium. For this purpose, the bottom panel of Table 4 reports the unweighted average value of the adjustment parameters estimated at the industry level, as well as their level of significance. The ECM term is found to amount to be 1.017, suggesting that the US manufacturing sector accommodates exogenous shocks nearly instantaneously. The economy closes the initial gap in one period but overshoots the equilibrium target. Therefore, the adjustment process is incomplete and continues until full convergence. Although the adjustment path toward the steady-state equilibrium is oscillatory, the convergence process is very rapid. In fact, the economy stably closes $99 \%$ of the initial gap only within one year but takes four years to reach the equilibrium. This finding is consistent with the predictions of the PEG framework concerning the absence of transitional dynamics. A similar finding is reported by Madsen et al. (2010a) in studying the development of the British economy from the First Industrial revolution onward. However, as Gemmell et al. (2011) document, this finding appears to reflect a rather general characteristic that is common to most industrialized economies. Inspecting the adjustment process at the individual industry level, it emerges that $53 \%$ of the industries (10 of 19) follow a convergence pattern, while for the remaining industries, there is evidence of no cointegration or, alternatively, of no convergence. 
Using labor productivity as an indicator of growth performance, we obtain similar findings for the long-term horizon. However, a larger number of industries systematically adjust to exogenous changes in the equilibrium values ( $74 \%$ of the total), following a monotonic path of convergence (the ECM term is 0.954). Although the adjustment toward the equilibrium is slower than that in col. (1), it remains very rapid: $99 \%$ of the initial disequilibrium gap is closed within one year, while full convergence is achieved within 6 years 34

The results of subsequent estimates broadly confirm the baseline estimates in cols. (1) and (2). However, a few points are worth mentioning. First, according to our more conservative estimates (col. 7), the US economy needs five years to close (almost entirely) the disequilibrium gap, confirming that the convergence process is extremely rapid. Moreover, the growth effect of $R \& D$ subsidies is far from stable; the coefficient sign of this variable varies remarkably with the type of control variables that are included in the specification. Sizeable changes can also be observed for the coefficients for the innovation rate and the tax price of the R\&D user cost. These results are likely due to the correlation among the overall set of regressors; for instance, product market competition is usually found to be a driver of innovation and patenting performance (see Aghion et al. 2013b and Franco et al. 2013 among others), and this may explain the increase in the coefficient for $\iota$ when we account for administrative barriers to competition in the analysis. In addition, all economic and policy controls are found to be significant and to have the expected signs (apart from external finance dependence). This result demonstrates the valuable improvement offered by the PMG estimation over the system regressions. Interestingly, when we include the average production tax rate, the coefficient for the $R \& D$ tax price decreases to -0.083 , likely as a result of the opposite effects exerted by these two policy instruments on economic growth. More important, the parameter for the $R \& D$ tax credit variable does not seem to capture the effect of R\&D effort, taken as a whole (col. 8) ${ }^{35}$ However, to determine whether the R\&D policy instrument variables have a direct impact on economic growth or, rather, reflect increased innovation effort associated with more favorable fiscal conditions or larger research grants, we include the cumulative value of predicted research expenses induced by changes in R\&D policy instruments. Following Bloom et al. (2013), we estimate a static R\&D demand equation in which research outlays are regressed on the one-year lagged values of our R\&D policy instruments and industry output (used as a proxy for sales). The value of research expenses predicted by $R \& D$ tax credit and $R \& D$ subsidies is then accumulated by using the perpetual inventory method to obtain the stock of $R \& D$ capital induced by innovation policies. This variable, expressed as a ratio over the real value added, is used as a control in the growth equation. We estimate the $\mathrm{R} \& \mathrm{D}$ demand equation by allowing for both homogeneous and heterogeneous parameters ${ }^{36}$ Despite the large disparity in the coefficient size of the regressors between such auxiliary specifications, using the two variants of

\footnotetext{
${ }^{34}$ As a robustness check on our specification design, we estimated a specification that restricts the impact of the regressors to the long run only. In principle, this specification is more consistent with the spirit of the PEG model regarding the lack of dynamics and the persistence in the effects of economic growth drivers. As expected, this regression had considerably lower explanatory power, validating the empirical counterpart of the PEG framework that is adopted in our paper. Similar findings arise for the TEG framework when one assumes that R\&D policy instruments affect the rate of economic growth only in the short run.

${ }^{35}$ One concern with this regression is that, likely due to misspecification problems, evidence regarding convergence toward the equilibrium from this specification is statistically weaker than that from previous estimates, and only $37 \%$ of our sample of industries adjusts toward the long-run values.

${ }^{36}$ Homogeneous parameter estimates are obtained by using the Newey-West estimator augmented with common correlated effects, as devised by Pesaran (2006). In this case, the coefficient for $R \& D$ tax price in the $R \& D$ demand estimation is -0.51 ( $p$-value $=0.015$ ), and that for R\&D subsidies is 0.062 (p-value 0.000 ), while the joint F-test that they are zero is 19.01 (p-value 0.000 ). The variable derived from such an auxiliary regression is used in col. (9). Col. (10) is instead based on a measure of policy-induced R\&D capital that is obtained by allowing for heterogeneous parameters in the R\&D demand estimation. We use the augmented mean estimator proposed by Eberhardt and Bond (2009), which yields the following values: -0.062 for the R\&D tax price (p-value 0.000 ), -0.060 for direct funding (p-value 0.067 ), and 20.76 for the joint F-test (p-value 0.000 ). The estimates are also applied below in the assessment of the TEG framework.
} 
the predicted variable does not change the conclusions regarding the direct effect of R\&D policy instruments on economic growth (see cols. 9 and 10). In addition, the predicted value of R\&D capital has a positive and significant coefficient, which is much smaller when it is derived from a heterogeneous parameter regression $(0.015$ vs 0.101$)$. As a result, such robustness checks indicate that innovation policies may not merely have an indirect effect on growth, which is typically channeled through increased levels of R\&D activity. In fact, the significance of the R\&D tax credit variable suggests that innovation policies likely generate a direct effect on GDP growth through a sustained demand expansion (consumption effect) enabled by a higher remuneration of R\&D factor inputs. ${ }^{37}$ R\&D policies may also raise the level of an array of activities related to R\&D (investment channel). For instance, the launch of a new state-of-the-art product may require a firm to design ad-hoc software systems, carry out marketing or advertising activities, or to invest in training or new workforce skills. These complementary investments take the form of intangible assets (Corrado et al., 2005).

Table 5 summarizes the results for the short-run effects. At the top, the table reports the average percentage of industries that, in regressions presented in Table 4, are found to benefit from a positive effect of R\&D policies (crowding-in effect). On average, we find a statistically significant relationship between policy instruments and output growth for two-thirds of the US manufacturing sectors. R\&D subsidies have more pervasive effects than fiscal incentives, however (35 vs. $28 \%$ of the total). There is a group of industries for which the growth-enhancing effect of direct funding is statistically stable across the specifications, holding in at least $50 \%$ of the regressions $(5$ of 10). The latter effect is particularly stable for Pharmaceuticals and Office machinery. This sector, together with Other instruments, Basic metals, Pulp, paper, and printing benefited from a more generous fiscal treatment of research outlays. However, in a portion of the sectors (over 50\%), one or both types of policy instruments were not conducive to economic growth over the short-term horizon (crowding-out effect). We do not list these sectors for the sake of simplicity. Nonetheless, we detail the sectors for which R\&D policies have adverse effects (in the bottom section of Table 4), which account for $27 \%$ of the overall sample: $7 \%$ receive a (statistically significant) positive net effect from innovation policies, $15 \%$ receive a net negative effect (mainly Food and Scientific instruments), and, on average, one sector (i.e., $5 \%$ ) does not gain any benefit from such policies, as the effects of the two types of policy instruments compensate for each other.

Now, we turn to the long-run estimates of the TEG framework (Table 6). Within this framework of analysis, the growth-enhancing effect of patenting and the R\&D tax price appears to be considerably stronger. Clearly, the finding regarding the $R \& D$ tax price is not consistent with the predictions of this theoretical setup, as well as evidence that $R \& D$ subsidies and relative $R \& D$ difficulty have a permanent effect on the rate of economic growth. Compared to the PEG framework, the PMG estimates provide an indication of a moderately slower (monotonic) process of adjustment toward the long-run equilibrium. In regression (1), the ECM term is estimated to be about -0.5. Therefore, it takes six years to close $99 \%$ of the initial disequilibrium gap, while it takes 20 years to fill in the residual $1 \%$. This result may be due to larger heterogeneity in the short-run growth process, as the range of converging industries is not larger with respect to the other growth setting (about two-thirds of the sample). The results for regressions that include control variables somewhat deviate from the baseline results (cols. 1 and 2). When we account for capital per worker or financial dependence, there is a drop in the coefficient for the innovation rate (0.2-0.3), and this variable turns out to be significant only at a $10 \%$ level in col. (4). On the other hand, in col. (5), the effect of the R\&D tax price is higher than that in all other regressions $(-0.17)$. In contrast to the

\footnotetext{
${ }^{37}$ A focused analysis on the impact of R\&D policies on researchers' wages can be found in Goolsbee (1998) and Lokshin and Mohnen (2013).
} 
results shown in Table 4, including the ratio between R\&D capital and value added reduces the parameter size of the R\&D tax price, whereas the effect of patenting doubles. However, although all parameters are correctly signed in this regression, one notable concern is that there is no evidence of cointegration, $\phi=0$, inhibiting inferences regarding the long-run estimates. A similar conclusion applies when we include the predicted cumulative value of R\&D induced by policy instruments, allowing for heterogeneous coefficients in the R\&D demand equation (col. 10). Relying on homogeneous parameters, the $R \& D$ tax credit variable is still found to permanently affect the rate of economic growth (col. 9) 38

As a last step, we examine the growth-enhancing effect of $R \& D$ policies over the short run (Table 7). Taken as a whole, policy instruments are found to promote economic growth in $54 \%$ of the sectors. This share is smaller than that found in the PEG formulation. In particular, there is indication of a less favorable short-run effect of R\&D tax credit (22\%). Apart from Office machinery, the group of industries denoting a more statistically robust effect from this policy instrument is confirmed by the PEG estimates (i.e., in at least $50 \%$ of the regressions). Conversely, the short-run effect of R\&D subsidies is less stable across the specifications, and we find a positive effect for this variable in fewer industries (cf. Table 5). The share of industries in which fiscal incentives and direct funding to $R \& D$ have adverse effects is also lower, and communication equipment is the only industry in which the net crowding-out effect of innovation policies appears to be relatively robust (i.e., confirmed in $50 \%$ of the TEG regressions).

\section{Discussion}

In this section, we first reconsider the predictions of the two competing theories, evaluating the empirical soundness of the growth mechanisms that underlie the two families of models. In making this assessment, we will focus on the role of innovation policies in the growth process. Second, we discuss our results with reference to the extant literature to put our analysis into perspective.

\subsection{Soundness of the growth mechanisms}

R\&D difficulty The two growth frameworks differ in how R\&D difficulty is modeled. The PEG formulation eliminates the scale effect by assuming that the level of $R \& D$ difficulty is proportional to the market size. This specification captures the notion that it is more difficult to introduce new products and to replace the old ones in a more crowded market. The TEG formulation, instead, eliminates the scale effect by introducing diminishing returns to $\mathrm{R} \& \mathrm{D}$ and assuming that individual researchers become less productive as the economy expands. Within this framework, the level of R\&D difficulty is increasing in the accumulated stock of effective innovation, which captures the notion that early discoveries select out easier inventions first, leaving the most difficult inventions for the future.

Basing on the system estimation of the innovation function and the R\&D difficulty equation, both formulations of $R \& D$ difficulty appear to be empirically well grounded. In both growth frameworks, the rate of patenting is positively related to the research input and negatively related to R\&D difficulty. Moreover, for the PEG economy, market size, as proxied by the number of product varieties that are available to the US market, is found to raise the level of R\&D difficulty in both the short and the long run. For the TEG economy, instead, the innovation rate has a positive impact on the rate at which $R \& D$ difficulty increases. These results indicate that both

\footnotetext{
${ }^{38}$ The long-run coefficient for the predicted variable on output growth is 0.019 in col. (9) and 0.034 in col. (10).
} 
mechanisms of eliminating the scale effect, namely, product proliferation for fully-endogenous growth theory and diminishing technological opportunities for semi-endogenous growth theory, have empirical foundations and are likely to complement each other.

Drivers of economic growth The two formulations of R\&D difficulty have significantly different implications for economic growth, however. The PEG specification allows for sustained per capita growth without population growth. Under this approach, policy measures alter the steady-state per capita growth rate and, therefore, have permanent effects on economic growth. By contrast, in the TEG specification, increasing difficulty of innovation causes the rate of economic growth to decrease over time unless an ever-increasing share of resources is invested in R\&D; thus, a growing population is required. Under this approach, policy measures such as innovation subsidies and tariffs affect economic growth only temporarily. These measures produce long-run effects on the level of $R \& D$ only, not on the steady-state growth rate of per capita income. Indeed, as ideas production (research) mainly relies on highly educated workers (researchers), the rate of economic expansion is ultimately restricted by the population growth rate.

The main findings of our analysis come from the assessment of innovation policies. Our evidence indicates that R\&D policy has a persistent, if not permanent, impact on economic growth: changes in innovation policies enhance the rate of economic growth in both the short and the long run. Moreover, the economy seems to adjust quite rapidly to such changes and, in less than five years, almost entirely closes the disequilibrium gap caused by exogenous shocks. These findings are consistent with the PEG approach, which predicts an instantaneous convergence of the economy to the equilibrium. Hence, the present work fills an important gap in the Schumpeterian growth literature, which, thus far, has not directly assessed the effects of policy factors on economic growth. According to our results, the impact of R\&D policy on economic growth results from the combination of a higher output of innovation activities and a demand expansion effect generated by a larger fraction of inputs allocated to R\&D (and their increased remuneration). However, large heterogeneity is found in the impact of R\&D policy instruments on economic growth. Indeed, only market-based incentives such as R\&D tax credits have a positive growth effect that is long lasting and statistically robust. Conversely, evidence regarding direct funding to research is rather ambiguous, as the growth effect of this policy instrument does not appear to be established and statistically robust. Larger R\&D subsidies are associated with an increase in the rate of economic growth in the short run only, indicating that, at best, this policy instrument has only temporary effects.

\subsection{Semi- vs. fully-endogenous growth}

As widely discussed throughout the paper, our work builds upon the recent body of empirical research testing the soundness of the latest developments of Schumpeterian growth theory. Zachariadis (2003) represents the first paper trying to test whether the predictions of second-generation growth models are consistent with the data, albeit based on a fully-endogenous growth model only 39 sing a panel of US industries over the period 1963-1988, the author estimates a system of interrelated equations linking $R \& D$ intensity and patenting to technological change and this, in turn, to economic growth, finding support for fully-endogenous growth models 40 The subsequent literature has

\footnotetext{
${ }^{39}$ Bottazzi and Peri (2007) show that the existence of a cointegrating relationship between the domestic stock of knowledge, domestic $\mathrm{R} \& \mathrm{D}$ and the international knowledge stock can be interpreted as supporting semi-endogenous rather than first-generation, fullyendogenous growth models.

40 Zachariadis (2004) draws a similar conclusion using aggregate data from a panel of 10 OECD countries and accounting for the impact of trade openness on productivity growth in accordance with Coe and Helpman (1995) and related papers. Empirical evidence in
} 
tried to discriminate between the two competing growth theories, mostly using cross-country or cross-industry data on innovation and productivity growth. These studies, building on the empirical specification proposed by $\mathrm{Ha}$ and Howitt (2007), provide evidence that fully endogenous growth theory better fits macroeconomic and industrial data (see, e.g., Madsen, 2008, Ang and Madsen, 2011 and Venturini, 2012b). This conclusion appears to have general validity and is not limited to certain countries and certain stages of development. Madsen et al. (2010a) model the transition to the post-Maltusian trap growth regime induced by the First Industrial Revolution in the British economy. They find that a crucial role in this process is played by innovation, and the impact of this factor reflects the pattern of fully-endogenous growth theory. Consistent results are obtained by Madsen (2010) in a growth-regression analysis conducted on a sample of OECD countries since the Second Industrial Revolution onwards. Similarly, Madsen et al. (2010b) consider the role of distance to frontier to quantify the impact of imitation and innovation in productivity growth of OECD and non-OECD member states. Furthermore, Madsen et al. (2010c) extend this kind of analyses to development issues, looking at the uptake of Indian economy. In a recent paper, Venturini (2012a) follows a different approach by developing a multi-equation framework of analysis in the spirit of Zachariadis (2003). The author compares the mechanism of product proliferation with that of diminishing technological opportunities finding that the semi-endogenous growth framework better describes innovation data for the US manufacturing sector.

Our paper contributes to this branch of literature in at least four respects. First, it builds a unified theoretical setting providing testable implications for both families of growth models. Second, it adopts an empirical strategy drawn upon the latest works on the area, for instance extending the multi-equation framework developed by Venturini (2012a) to test several R\&D technologies to the analysis of economic growth. Third, it empirically investigates the effectiveness of innovation policies, an issue that has not been explored in earlier studies. Four, in assessing the predictions of the two competing theories, it analyses both the steady-state and dynamic properties of these models. As emphasized by Ha and Howitt (2007), this issue appears crucial in reference to the possibility that, over the short-term horizon (i.e., outside the equilibrium stadium), some assumptions making the theoretical predictions testable may not be satisfied. For instance, in the short run, employment may not closely covary with population, and this ends up compromising most of the steady-state analyses that use the former variable as a proxy for population and consumer demand.

\subsection{R\&D policies and economic growth}

Our analysis allows us to draw some important conclusions about R\&D policy. From this perspective, the present work relates to the large body of research inspecting the role of public support to R\&D, which typically takes the form of direct public engagement, direct subsidies, tax credit or public procurement. This literature has concentrated on two major questions: (1) the additionality issue, i.e., whether public support raises, or reduces, private $R \& D$ investment (crowding-in or crowding-out effect); and (2) whether R\&D tax credits are more or less effective than direct subsidies in stimulating business R\&D.

The evidence on these points is very extensive but, nevertheless, remains quite controversial 41 Using US

support of fully-endogenous growth theory is also found in Ulku (2007) and Ertur and Koch (2011). Ulku (2007) provides an empirical analysis of the relationship between R\&D intensity, the rate of innovation and the growth rate of output in four manufacturing sectors from 17 OECD countries. Ertur and Koch (2011) introduce worldwide interdependence, implied by international R\&D spillovers, in a generalized Schumpeterian growth model with technological interactions. The authors compare this framework to a multi-country Solow growth model and show that the former model provides a better explanation of the growth process.

${ }^{41}$ For the sake of brevity, we mostly concentrate on the evidence based on industry- and country-level data. The interested reader may refer to the surveys by David et al. (2000) and Alonso-Borrego et al. (2014) for a more comprehensive assessment of this literature. 
company data Scott (1984), Levin and Reiss (1984) and Leyden and Link (1991) show that public R\&D is complementary to private R\&D. In a series of papers, Lichtenberg (1984, 1987, 1988) has re-examined this issue, finding evidence of crowding-out effects. With the diffusion of the R\&D tax credit nationally and among the U.S. states since the early 1980s, much of the debate has centered on evaluating whether tax credits are more effective than direct subsidies in stimulating business R\&D. Using industry-level data, Mamuneas and Nadiri (1996) document that incremental $R \& D$ tax credit and the immediate deductibility provision of $R \& D$ expenditures have a significant impact on privately-funded R\&D investment; on the other hand, publicly-financed R\&D induces cost savings but crowds out privately-funded R\&D investment. Guellec and Van Pottelsberghe De La Potterie (2003) show that, in OECD countries, direct government funding spurs business-financed R\&D apart from when it is oriented towards defence; tax incentives have mainly short-lived effects. These policy instruments act as substitutes as increased intensity of one reduces the effect of the other on business R\&D $4^{42}$ Wilson $(2009)$ considers the implications of the R\&D tax credit policy across the US states and shows that fiscal incentives provided by neighbouring states crowd out in-state R\&D. Bloom et al. (2002) quantify the impact of fiscal incentives on R\&D investment by estimating an R\&D demand equation for a sample of OECD countries. They find that a ten percent fall in the cost of R\&D stimulates over a one percent rise in the R\&D effort in the short run, and almost a ten percent increase over the long run 43 Our paper contributes to this strand of studies showing that, within a Schumpeterian economy, market-based fiscal incentives are more effective in enhancing innovation and growth compared to direct subsidies. The latter policy measures are effective in promoting growth only in the short run, but not over a long-term horizon when they appear unfit to tackle the detrimental effect of R\&D difficulty fuelled by product proliferation (fully-endogenous growth) or the increasing technological complexity of innovation (semi-endogenous growth).

In the R\&D literature, the channels through which the microeconomic effects of innovation policies translate into aggregate outcomes have remained almost unexplored. Firms adapt slowly, or with some lag, their R\&D plans to the introduction of new incentives, implying that the impact of $R \& D$ policies on recipients is more pronounced over the long run. Furthermore, current R\&D can be influenced by past research effort and, in the extent to which the latter has been influenced by temporary R\&D grants, innovation policy might be effective even after the support has expired (Klette et al., 2000). Although the effect of innovation policy may transmit from percipient (treated) to other (untreated) firms because of knowledge spillovers, the benefits gained individually may not reverberate on macroeconomic performance due to the aggregation effects existing across companies: for instance, product market rivalry awards only few innovative firms within each sector, whereas most struggle or exit the market (Bloom et al. 2013). At the firm level, the mechanism of transmission of R\&D policy to the output of innovation performance (patents, the share of innovative products in total sales, etc.), as well as to productivity or profitability performance has been studied through the framework developed by Crepon et al. (1998). These effects are indirect as mediated by R\&D effort and, accordingly, are respectively referred to as second- and thirdorder effects of R\&D policy (Mohnen and Lokshin, 2009). Our paper brings this type of analyses on the ground of

\footnotetext{
${ }^{42}$ Evidence outside the US is still scant. Focused EU analyses on this issue, based on firm-level data, are Busom et al. (2012) and Czarnitzki and Toivanen (2013).

4These authors also show that heterogeneity in the impact of R\&D policies is large across countries and moderate at industry level: aerospace is the only sector where $R \& D$ tax price is not significant, probably as benefiting from huge direct public provisions. Conversely, the effect of R\&D fiscal incentives is stable over time. There is also an extensive theoretical literature that aims to investigate the aggregate implications of changes in innovation policy. See Jones and Manuelli (2005) for an interesting review of the impact of policies on growth in neoclassical endogenous growth models. See Segerstrom (2000), Jones and Williams (2000) and the recent work by Atkeson and Burstein (2011) for a discussion of the role of R\&D policy in non-scale growth models.
} 
macroeconomics and industrial organization. We provide testable reduced-form specifications derived from a model of structural equations depicting the sequence of microeconomic effects of innovation policy. Our empirical setting allows us to identify the overall impact of $R \& D$ policy on economic growth, irrespective of whether this effect is driven by a higher R\&D effort and patent performance, by innovation activities complementary or independent on formal research, and by a demand expansion associated with the larger fraction of income paid to research inputs. From this point of view, our analysis extends the recent work by Westmore (2013). The author examines first- and higher-order effects of innovation policies in OECD countries by considering separately the relationship between various $R \& D$ policy instruments and $R \& D$ effort, and between these and per-capita patents and total factor productivity growth. Differently from this paper, we find that R\&D tax credit influences the growth rate of industry output beyond the direct effects on research and patenting. This result is robust to controlling for the effect of other public policies (competition policies and fiscal burden on production), for differences in industry structural characteristics (financial dependence, skill or capital intensity), as well as to some econometric issues (dynamic adjustment, parameter heterogeneity, etc.). Consistently with Westmore (2013), we detect that the effect of direct funding is not statistically robust in the long run, at least if we consider the elapse of time common to both studies (up to 2000).

\subsection{Public policies and economic growth}

Another strand of literature to which our paper is related is that looking at the nexus between fiscal policy and economic growth. This body of research has tried to answer the questions of how tax policy affects economic growth and whether these effects are short-lived or permanent.

On the theoretical front, starting from the Nineties, a number of authors have proposed endogenous growth models that successfully lay out the channels through which tax-policy changes affect the rate of capital accumulation (human and physical), labor-leisure tradeoffs, and thereby economic growth (see, e.g., Barro, 1990; King and Rebelo, 1990, and Jones et al., 1993). These papers show that the effects can even be long-lasting, meaning that the level of output and eventually the rate of economic growth are affected not only during the short-run adjustment process, but also in the steady state.

Instead, less conclusive results emerge from the empirical strand of this literature. In standard cross-country growth regressions, Easterly and Rebelo (1993) find that measures of fiscal policies tend to be insignificantly related with growth. A similar conclusion is obtained by Mendoza et al. (1997) using an influential empirical approach to assess the predictions of neo-classic growth theory that higher tax rates discourage investment and affect negatively economic growth ${ }^{44}$ This issue has been further investigated by a number of subsequent studies and refined in several respects (see, e.g., Kneller et al., 1999, Arnold et al., 2011; Gemmell et al., 2011). These more recent contributions have specifically looked at how changes in the tax structure rather than changes in the overall tax burden affect either the income level or the rate of economic growth over the medium- and long-term horizons. In contrast with earlier evidence, these works suggest that there exists a robust and significant association between taxation and growth. For instance, Gemmell et al. (2011) study the timing and persistence in the impact of fiscal policies on economic growth by applying an error-correction-mechanism framework to a sample of OECD countries. Two main findings can be drawn from this work: i) public policies have the largest growth impact in

\footnotetext{
${ }^{44}$ This ambiguity gives support to the so-called "Harberger's super-neutrality conjecture". Using a growth-accounting framework, Harberger (1964) shows that changes in the mix of direct and indirect taxes produce a negligible effect on output growth as they do not significantly affect labor supply and labor's income share, while having only little impact on saving and investment rates.
} 
the short run, and this effect persists over time if there is no policy reversal; and ii) the negative growth impact of distortionary tax changes is counteracted by the positive effect associated with changes in productive public spending. Using an open-economy growth setting, Gemmell et al. $($ 2013) show the mechanism behind the negative impact of taxation: tax effects on GDP growth operate largely through changes in factor productivity, rather than in factor accumulation 45 This mechanism is consistent with the view developed in some recent theoretical contributions (see Peretto, 2003, 2007) showing that, in the context of a model of Schumpeterian growth, the taxgrowth effects are transmitted via innovation instead of via investment. To the best of our knowledge, our paper is the first taking a similar approach of analysis to study the channel of transmission from $\mathrm{R} \& \mathrm{D}$ policies to economic growth. In doing so, we build a consistent setting based on the most recent developments of (scale-invariant) R\&D-based growth theory 46

\section{Conclusion}

In the last few years, a growing body of empirical research has tried to test whether the predictions of secondgeneration growth models are consistent with the data. This strand of research is silent on whether innovation policies have permanent or temporary effects on economic growth. This issue has remained un-addressed so far because most of these studies build on the empirical framework proposed by Ha and Howitt (2007) which suitably describes the long-run properties of growth models but does not contemplate an explicit role for R\&D policy.

In the present paper, we fill this gap in the literature by providing a unified growth setting that is empirically tested on US manufacturing industry data. Our theoretical set-up builds on a scale-invariant R\&D growth model based on the quality-ladder framework developed by Grossman and Helpman (1991). We eliminate the scale effect by considering two alternative specifications for R\&D difficulty which lead to two competing versions of the model, one for semi-endogenous growth and one for fully-endogenous growth. We empirically test the predictions of the two growth set-ups for R\&D policies adopting various techniques of dynamic panel data (cointegration) regression. Our analysis shows that the impact of fiscal incentives to R\&D is long lasting and statistically robust. Conversely, we find that $R \& D$ subsidies increase $R \& D$ effort and the rate of economic growth in the short run. Over the long-term horizon, in fact, there is no significant effect from this policy instrument, indicating that, at best, R\&D subsidies have temporary effects on economic growth. Another valuable insight of our analysis concerns the role of R\&D difficulty. Our system estimates indicate that both mechanisms of sterilization of the scale effect, are empirically well grounded. One caveat of our analysis is that our estimation results are inconclusive on whether product proliferation or diminishing technologically opportunities also reverberate on the rate of economic growth, as postulated by theoretical models. Indeed, the growth effects of such forces are far from being stable in our estimates. This issue requires further assessment in the future.

There are various extensions to this line of research. First, the framework could be extended to an openeconomy context and estimated on cross-country, cross-industry data. This extension is relevant because it would allow us to address the issue of R\&D policy competition among countries and evaluate its impact on aggregate

\footnotetext{
${ }^{45}$ See Bergh and Henrekson (2011) for a survey of the literature on the relationship between taxes, government size and economic growth.

${ }^{46} \mathrm{R} \& \mathrm{D}$ policy is only one form of public policy intervention in the process of innovation. An important body of research has recently flourished within the Schumpeterian tradition, providing new insights on the relationships between patent protection and product market competition on innovation and growth (see Aghion et al., 2013a b). This strand of literature supports the view that patent protection and product market competition act as complementary inputs to innovation and growth, at odds with what early endogeneous growth models predict (see, e.g., Romer, 1990, Aghion and Howitt, 1992).
} 
outcomes of an economy. Another important extension would be to incorporate various types of spillovers both within and across industries into a multi-country setting. In a recent article, Bloom et al. (2013) use a general analytical framework to study the implications of both technology and product market spillovers on a range of firm performance indicators. This perspective of analysis could be nicely used to assess the role of spillovers on economic growth. Finally, following Dinopoulos and Syropoulos (2007), we could formalize the idea that incumbents in a particular industry undertake rent protection activities to raise the level of R\&D difficulty for newcomers who target their innovation efforts at this industry. It would be interesting to investigate empirically the robustness of this mechanism that gives rise to an alternative formulation of the fully-endogenous growth model. These issues are the focus of our future research. 
Table 1: Summary statistics

\begin{tabular}{llrrrr}
\hline \hline \multicolumn{1}{c}{ Variable } & & Mean & S. D. & Min. & Max. \\
\hline Innovation rate & $\iota$ & 0.159 & 0.039 & 0.071 & 0.29 \\
Output growth & $\Delta \ln Y$ & 0.063 & 0.138 & -0.341 & 0.677 \\
R\&D input & $L_{I}$ & 248.3 & 330.2 & 0.095 & 1732 \\
Product variety & $L$ & 2060 & 1916 & 91 & 9285 \\
Product variety growth & $n$ & 0.002 & 0.264 & -2.884 & 1.441 \\
Employment growth & $n$ & 0.004 & 0.047 & -0.225 & 0.201 \\
R\&D difficulty & $X$ & 17.49 & 12.21 & 2.960 & 116.8 \\
R\&D difficulty growth & $\Delta \ln X$ & 0.015 & 0.537 & -1.937 & 1.885 \\
Normalized R\&D difficulty (PEG) & $x=X / L$ & 0.250 & 0.433 & 0.005 & 5.095 \\
Normalized R\&D difficulty (TEG) & $x=X / L$ & 0.033 & 0.037 & 0.002 & 0.224 \\
R\&D tax price & $s$ & 1.348 & 0.138 & 1.164 & 1.525 \\
R\&D subsidy & $s$ & 0.120 & 0.182 & 0.001 & 0.775 \\
\hline
\end{tabular}

Notes: R\&D is expressed in billions of USD at 1995 prices. Normalized R\&D difficulty $(\mathrm{PEG}) \times 100,000$. Industry list: Food, beverage \& tobacco (ISIC 15t16); Textile, leather \& footwear (17t19); Pulp, paper, printing \& publishing (21t22); Chemicals (24); Pharmaceuticals (244); Rubber \& plastic (25); Other non-metallic mineral (26); Basic metals (27); Fabricated metal products (28); Machinery (29); Office machinery (30); Electrical machinery (31); Electronic valves (321); Communication equipment (322t3); Scientific instruments (331); Other instruments (332); Motor vehicles (34); Other transport equipment (35); Wood and Manufacturing NEC (320, $6 \mathrm{t} 37)$. 
Table 2: PEG: Dynamic structural model

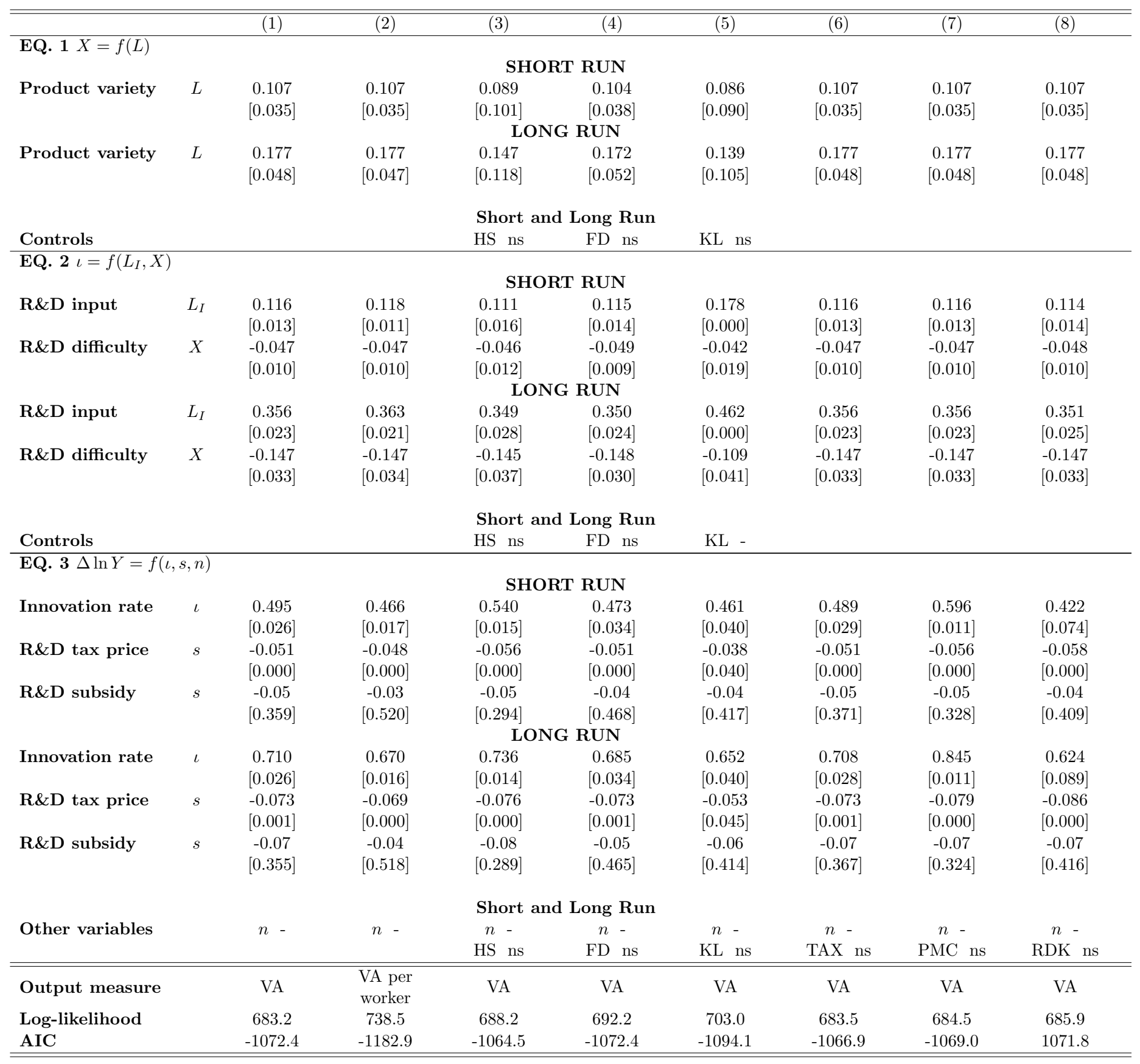

Notes: SUR estimates. EQ. 1: Dependent variable = R\&D difficulty. It includes industry-specific fixed effects and common time dummies. EQ. 2: Dependent variable $=$ innovation rate. It includes industry-specific fixed effects and time trends. EQ. 3: Dependent variable $=$ Output growth. It includes industry-specific fixed effects and common time dummies. $V A=$ Value added. Other variables: $n=$ Product variety growth, $H S=$ high-skilled labour share, $F D=$ external financial dependence, $K L=$ capital/labour ratio. $R D K=\mathrm{R} \& \mathrm{D}$ capital/value added, $T A X=$ production tax rate, $P M C=$ upstream product market competition. + positively significant at least $10 \%,-$ negatively significant at least $10 \%, n s=$ not significant. P-value in brackets. Obs. 399. 
Table 3: TEG: Dynamic structural model

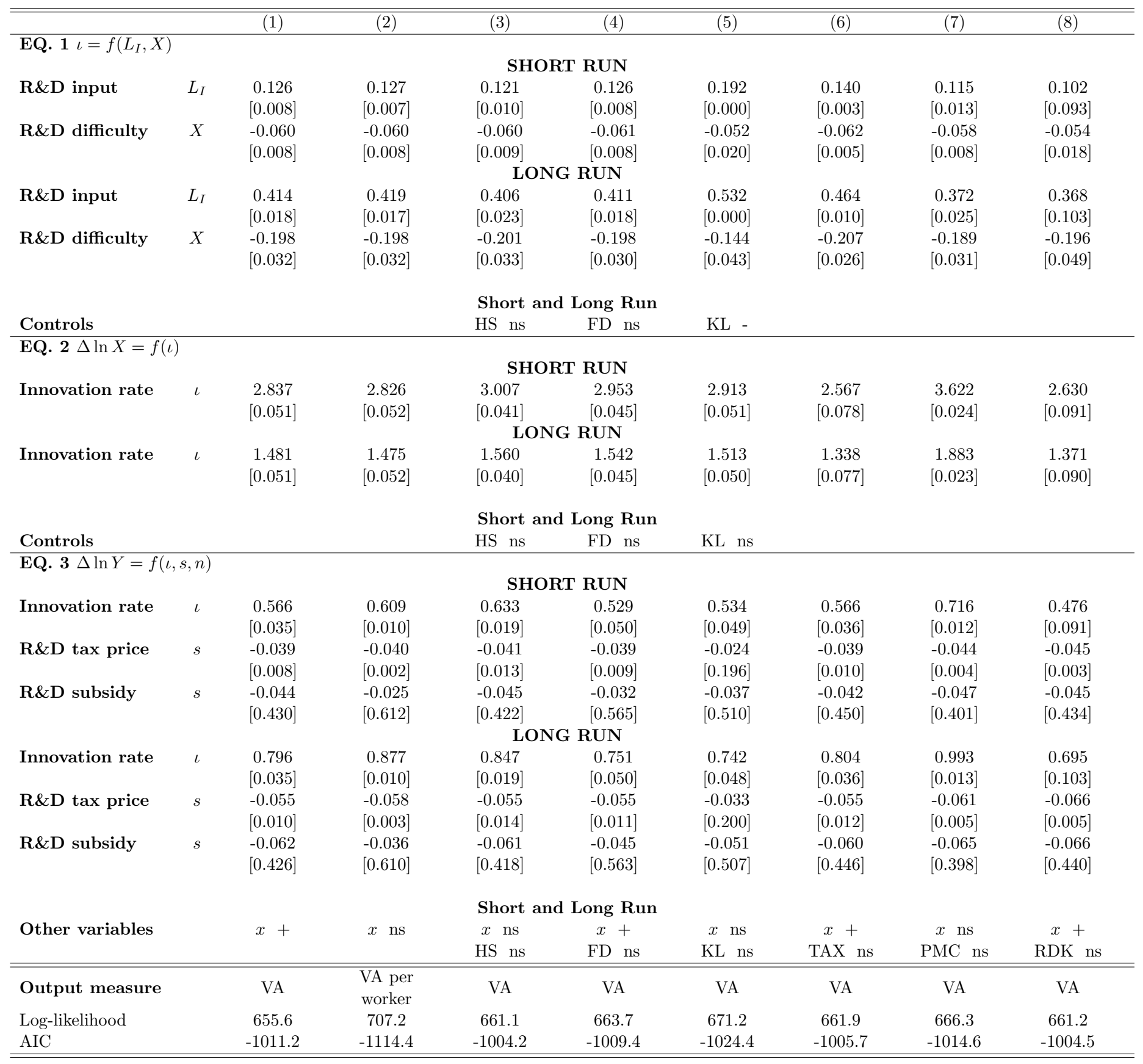

Notes: SUR estimates. EQ. 1: Dependent variable = innovation rate. It includes industry-specific fixed effects and time trends. EQ. 2: Dependent variable $=R \& D$ difficulty growth. It includes industry-specific fixed effects and common time dummies. EQ. 3: Dependent variable $=$ Output growth. It includes industry-specific fixed effects and common time dummies. $V A=$ Value added. Other variables: $x=$ Relative R\&D difficulty, $H S=$ high-skilled labour share, $F D=$ external financial dependence, $K L=$ capital/labour ratio. $R D K=\mathrm{R} \& \mathrm{D}$ capital/value added, $T A X=$ production tax rate, $P M C=$ upstream product market competition. + positively significant at least $10 \%,-$ negatively significant at least $10 \%$, $n s=$ not significant. P-value in brackets. Obs. 399 . 
Table 4: Long-run homogeneous effects on growth (PEG): PMG estimates

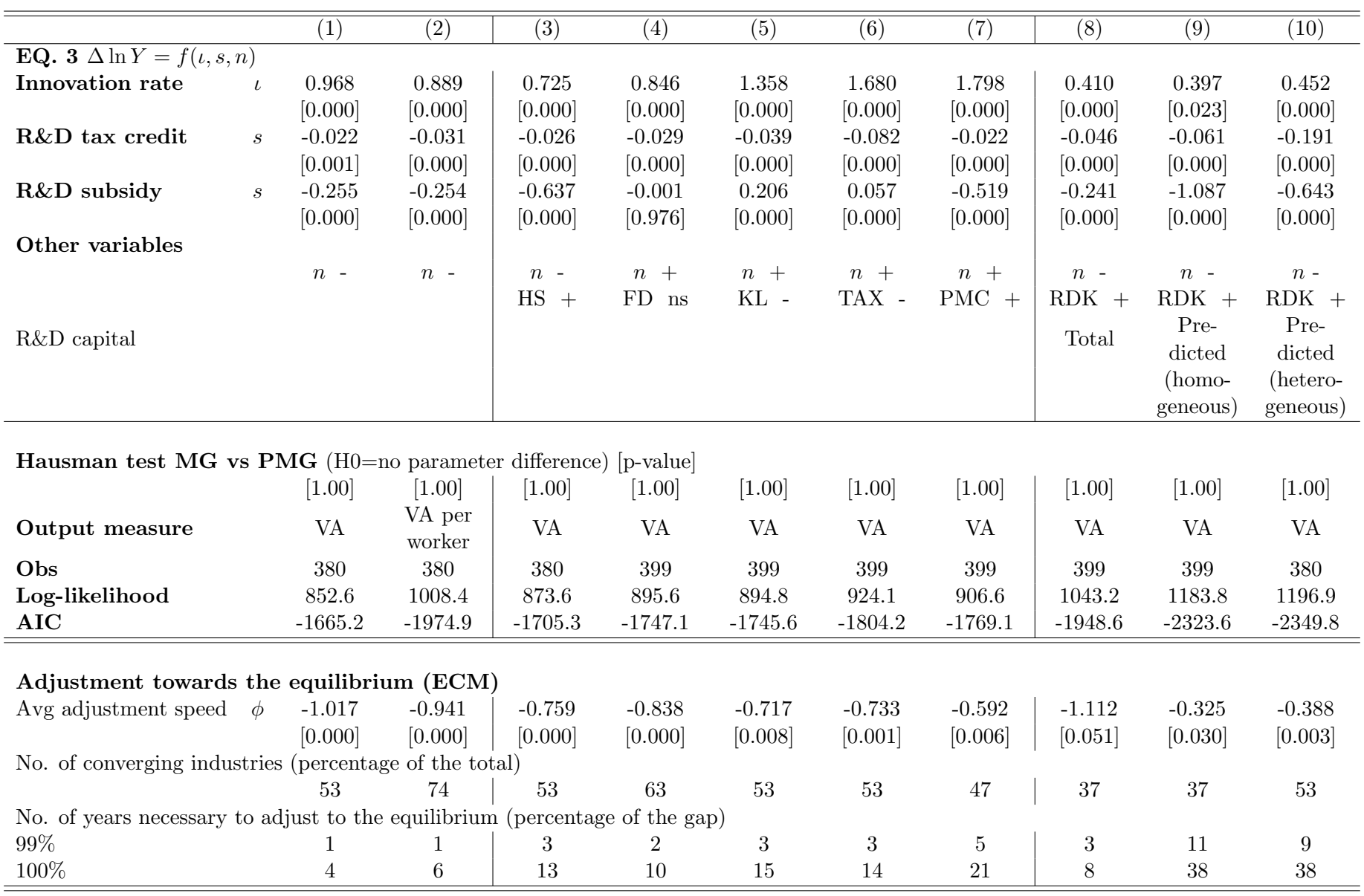

Notes: PMG estimates. Dependent variable $=$ Output growth. It includes industry-specific fixed effects and common time dummies. $V A=$ Value added. Other variables: $n=$ Product variety growth, $H S=$ high-skilled labour share, $F D=$ external financial dependence, $K L=$ capital/labour ratio. $R D K=\mathrm{R} \& \mathrm{D}$ capital/value added, $T A X=$ production tax rate, $P M C=$ upstream product market competition. + positively significant at least $10 \%,-$ negatively significant at least $10 \%, n s=$ not significant. P-value in brackets. 
Table 5: Short-run heterogeneous effects of R\&D policies (PEG)

\begin{tabular}{|c|c|c|}
\hline \multirow{3}{*}{ TOTAL } & \multicolumn{2}{|r|}{ Industries with positive effects } \\
\hline & $\%$ of total & $\%$ of regressions in Table 4 \\
\hline & 63 & $\geq 50 \% \quad \geq 75 \% \quad=100 \%$ \\
\hline R\&D tax credit & 28 & $\begin{array}{l}\text { PUL, BAS, OFF, } \\
\text { OTI }\end{array}$ \\
\hline \multirow[t]{4}{*}{ R\&D subsidy } & 35 & $\begin{array}{l}\text { TEX, BAS, ELE, } \\
\text { COM, SCI, MOT }\end{array}$ \\
\hline & \multicolumn{2}{|r|}{ Industries with adverse effects } \\
\hline & $\%$ of total & $\%$ of regressions in Table 4 \\
\hline & & $\geq 75 \% \quad=100 \%$ \\
\hline TOTAL & 25 & \\
\hline Net positive & 6 & \\
\hline Net negative & 14 & FOO, SCI \\
\hline Net null & 5 & \\
\hline
\end{tabular}

Industry list. FOO: Food, beverage \& tobacco (ISIC 15t16). TEX: Textile, leather \& footwear (17t19). PUL: Pulp, paper, printing \& publishing (21t22). CHE: Chemicals (24). PHA: Pharmaceuticals (244). RUB: Rubber \& plastic (25). ONM: Other non-metallic mineral (26). BAS: Basic metals (27). FAB: Fabricated metal products (28). MAC: Machinery (29). OFF: Office machinery (30). ELE: Electrical machinery (31). ELV: Electronic valves (321). COM: Communication equipment (322t3). SCI: Scientific instruments (331). OTI: Other instruments (332). MOT: Motor vehicles (34). OTV: Other transport equipment (35). OTM: Wood and Manufacturing NEC $(320,36 \mathrm{t} 37)$. 
Table 6: Long-run homogeneous effects on growth (TEG): PMG estimates

\begin{tabular}{|c|c|c|c|c|c|c|c|c|c|c|c|}
\hline & & $(1)$ & $(2)$ & $(3)$ & $(4)$ & $(5)$ & $(6)$ & $(7)$ & $(8)$ & $(9)$ & $(10)$ \\
\hline \multicolumn{12}{|c|}{ EQ. $3 \Delta \ln Y=f(\iota, s, x)$} \\
\hline \multirow[t]{2}{*}{ Innovation rate } & $\iota$ & 1.144 & 1.338 & 1.691 & 0.204 & 0.264 & 0.864 & 0.993 & 1.853 & 2.052 & 1.610 \\
\hline & & {$[0.000]$} & {$[0.000]$} & {$[0.000]$} & {$[0.089]$} & {$[0.031]$} & {$[0.000]$} & {$[0.000]$} & {$[0.000]$} & {$[0.000]$} & {$[0.000]$} \\
\hline \multirow[t]{2}{*}{ R\&D tax credit } & $s$ & -0.119 & -0.084 & -0.028 & -0.074 & -0.179 & -0.027 & -0.086 & -0.019 & -0.111 & -0.043 \\
\hline & & {$[0.000]$} & {$[0.000]$} & {$[0.000]$} & {$[0.000]$} & {$[0.000]$} & {$[0.000]$} & {$[0.000]$} & {$[0.016]$} & {$[0.000]$} & {$[0.000]$} \\
\hline \multirow[t]{2}{*}{ R\&D subsidy } & $s$ & -0.577 & -0.256 & 0.036 & 0.14 & 0.351 & 0.149 & -0.503 & 0.071 & -1.063 & 0.419 \\
\hline & & {$[0.000]$} & {$[0.000]$} & {$[0.026]$} & {$[0.000]$} & {$[0.000]$} & {$[0.000]$} & {$[0.000]$} & {$[0.008]$} & {$[0.000]$} & {$[0.000]$} \\
\hline \multicolumn{12}{|l|}{ Other variables } \\
\hline \multirow[b]{2}{*}{ R\&D capital } & & $x+$ & $x+$ & $x-$ & $x-$ & $x-$ & $x-$ & $x-$ & $x-$ & $x+$ & $x+$ \\
\hline & & & & $\mathrm{HS}+$ & $\mathrm{FD}+$ & $\mathrm{KL}-$ & TAX ns & $\mathrm{PMC}+$ & $\begin{array}{c}\text { RDK + } \\
\text { Total }\end{array}$ & $\begin{array}{c}\text { RDK + } \\
\text { Pre- } \\
\text { dicted } \\
\text { (homo- } \\
\text { geneous) }\end{array}$ & $\begin{array}{c}\text { RDK + } \\
\text { Pre- } \\
\text { dicted } \\
\text { (hetero- } \\
\text { geneous) }\end{array}$ \\
\hline \multicolumn{12}{|c|}{ Hausman test $\mathbf{M G}$ vs PMG ( $\mathrm{H} 0=$ no parameter difference) [p-value] } \\
\hline p-value & & {$[1.00]$} & {$[1.00]$} & {$[1.00]$} & {$[1.00]$} & {$[1.00]$} & {$[1.00]$} & {$[1.00]$} & {$[1.00]$} & {$[1.00]$} & {$[1.00]$} \\
\hline \multicolumn{2}{|l|}{ Output measure } & VA & $\begin{array}{l}\text { VA per } \\
\text { worker }\end{array}$ & VA & VA & VA & VA & VA & VA & VA & VA \\
\hline \multicolumn{2}{|l|}{ Obs } & 399 & 399 & 399 & 418 & 418 & 418 & 418 & 418 & 418 & 399 \\
\hline \multicolumn{2}{|l|}{ Log-likelihood } & 1005.8 & 985.3 & 874.9 & 863.0 & 805.8 & 912.9 & 990.0 & 968.6 & 1241.3 & 1069.3 \\
\hline \multicolumn{2}{|l|}{ AIC } & -1967.6 & -1928.6 & -1707.8 & -1682.1 & -1571.6 & -1781.7 & -1934.0 & -1891.1 & -2436.6 & -2094.5 \\
\hline \multicolumn{12}{|c|}{ Adjustment towards the equilibrium (ECM) } \\
\hline \multirow[t]{2}{*}{ Avg adjustment speed } & $\phi$ & -0.509 & -0.701 & -0.882 & -0.631 & -0.484 & -0.848 & -0.676 & -0.334 & -0.358 & -0.078 \\
\hline & & {$[0.000]$} & {$[0.000]$} & {$[0.006]$} & {$[0.003]$} & {$[0.014]$} & {$[0.000]$} & {$[0.010]$} & {$[0.412]$} & {$[0.011]$} & {$[0.729]$} \\
\hline \multicolumn{12}{|c|}{ No. of converging industries (percentage of the total) } \\
\hline & & 68 & 58 & 58 & 58 & 53 & 58 & 63 & 26 & 53 & 47 \\
\hline \multicolumn{12}{|c|}{ No. of years necessary to adjust to the equilibrium (percentage of the gap) } \\
\hline $99 \%$ & & 6 & 3 & 2 & 4 & 6 & 2 & 4 & nc & 10 & nc \\
\hline $100 \%$ & & 26 & 15 & 8 & 19 & 28 & 10 & 16 & nc & 43 & $\mathrm{nc}$ \\
\hline
\end{tabular}

Notes: PMG estimates. Dependent variable $=$ Output growth. It includes industry-specific fixed effects and common time dummies. $V A=$ Value added. Other variables: $x=$ Relative R\&D difficulty, $H S=$ high-skilled labour share, $F D=$ external financial dependence, $K L=$ capital/labour ratio. $L_{I} / V A=\mathrm{R} \& \mathrm{D}$ capital/value added, $T A X=$ production tax rate, $P M C=$ upstream product market competition. + positively significant at least $10 \%,-$ negatively significant at least $10 \%, n s=$ not significant. $n c=$ no convergence. P-value in brackets. 
Table 7: Short-run heterogeneous effects of R\&D policies (TEG)

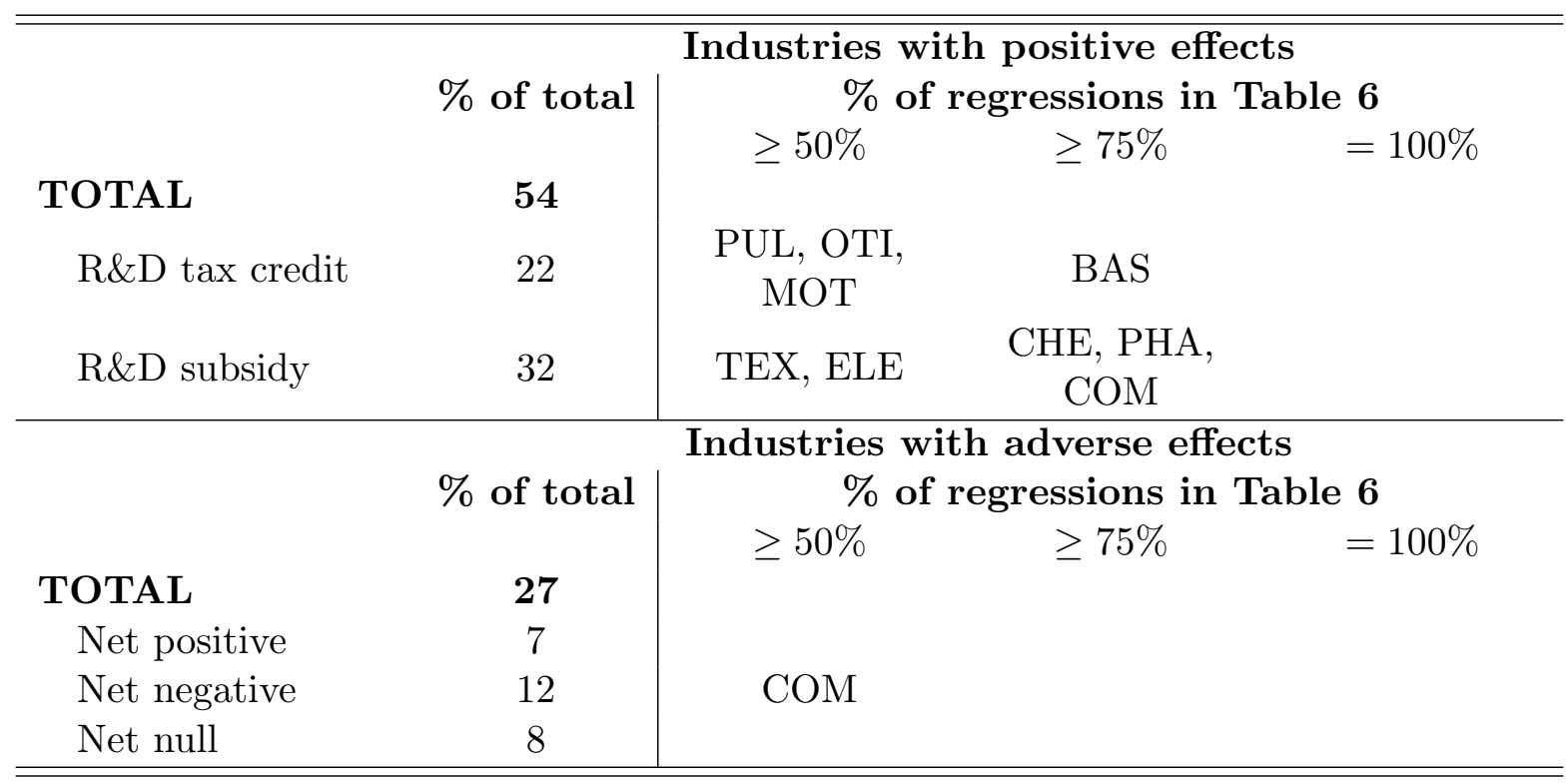

Industry list. FOO: Food, beverage \& tobacco (ISIC 15t16). TEX: Textile, leather \& footwear (17t19). PUL: Pulp, paper, printing \& publishing (21t22). CHE: Chemicals (24). PHA: Pharmaceuticals (244). RUB: Rubber \& plastic (25). ONM: Other non-metallic mineral (26). BAS: Basic metals (27). FAB: Fabricated metal products (28). MAC: Machinery (29). OFF: Office machinery (30). ELE: Electrical machinery (31). ELV: Electronic valves (321). COM: Communication equipment (322t3). SCI: Scientific instruments (331). OTI: Other instruments (332). MOT: Motor vehicles (34). OTV: Other transport equipment (35). OTM: Wood and Manufacturing NEC $(320,36 \mathrm{t} 37)$. 


\section{Appendix}

\section{A PEG}

The model under the PEG specification does not exhibit transitional dynamics. To ascertain this, note that the full employment of labor condition must hold in each instant in time because, by assumption, factor markets clear instantaneously. Solving the labor market clearing condition for the rate of innovation, $\iota_{t}$, and substituting the resulting expression in (5) yields a differential equation in consumption per-capita:

$$
\dot{c}_{t}=c_{t}\left[\left(\frac{\lambda-1}{1-s}+1\right) \frac{c_{t}}{\lambda b \kappa}-\left(\rho-n+\frac{1}{b \kappa}\right)\right]
$$

where we have used the fact that $x_{t} \equiv X_{t} / L_{t}=\kappa$ and $\dot{X}_{t} / X_{t}=n$. The evolution of the rate of innovation $\iota_{t}$ for any value of $c_{t}$ is determined by the labor market clearing condition:

$$
1=c_{t} / \lambda+\iota_{t} b \kappa
$$

Setting the square-bracket expression in A.1 equal to zero gives the steady-state per-capita consumption expenditure $c>0$, which is consistent with the positive rate of innovation ( $\iota$-PEG). Because consumption expenditure and $R \& D$ services are all choice variables, the economy jumps instantaneously to the steady-state equilibrium at time zero. Any other trajectory is inconsistent with the profit-maximizing behavior of firms.

For values of per-capita consumption that are less than $c$ the right-hand side of (A.1) is negative. Consequently, the economy approaches a steady-state with zero per-capita consumption expenditure. This trajectory implies that, with $c=0$, firms engage in R\&D investment even if the flow of profits (2) and the reward to innovation (3) are zero. This is in contradiction with the assumption that firms maximize expected discounted profits when investing in $\mathrm{R} \& \mathrm{D}$ activities.

Similarly, for values of per-capita consumption higher than $c$ the right-hand side of (A.1) is positive. Thus, the market interest rate is higher than the subjective discount rate and $\dot{c}_{t} / c_{t}>0$. In this case, the full employment of labor condition $(\mathrm{A} .2)$ implies that the economy experiences positive growth in per-capita consumption expenditure with no innovation. This trajectory implies that, with $\iota=0$, the level of $\mathrm{R} \& \mathrm{D}$ investment is zero, per-capita consumption expenditure grows exponentially, and all labor is allocated to manufacturing. Because $\dot{c}_{t} / c_{t}>0$, the reward to innovation (3) increases over time. The latter contradicts the fact that firms do not engage in $R \& D$ activities.

\section{B TEG}

Following (Segerstrom, 1998, pp. 1299-1300), we investigate the transitional dynamic properties of the model under the TEG specification. Differentiating relative $\mathrm{R} \& \mathrm{D}$ difficulty $x(t)$ with respect to time yields $\dot{x}_{t} / x_{t}=\mu \iota_{t}-n$. Substituting for $\iota(t)$ using the labor market clearing condition yields one differential equation that has to be satisfied along any equilibrium path:

$$
\dot{x}_{t}=\frac{\mu}{b}\left(1-\frac{c_{t}}{\lambda}\right)-n x_{t} .
$$



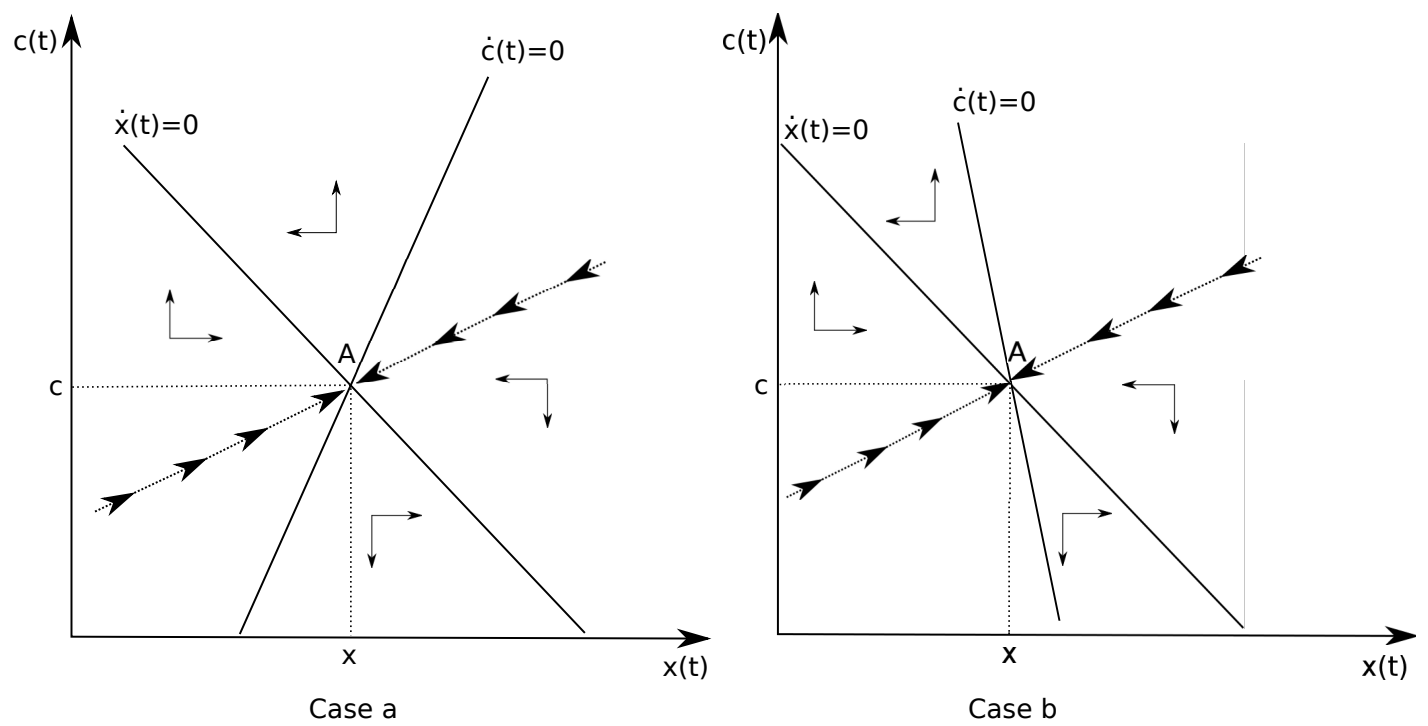

Figure 1: Stability of the balanced growth equilibrium

Because the right-hand side of (B.1) is decreasing in both $x_{t}$ and $c_{t}$, we conclude that $\dot{x}_{t}=0$ is a downwardsloping curve. Starting from any point on this curve, an increase in $x_{t}$ leads to $\dot{x}_{t}<0$ and a decrease in $x_{t}$ leads to $\dot{x}_{t}>0$, as shown by the horizontal arrows in Figure 1. Solving the labor market clearing condition for the rate of innovation, $\iota_{t}$, and substituting the resulting expression in (5) yields a differential equation in consumption per-capita:

$$
\dot{c}_{t}=c_{t}\left[\left(\frac{\lambda-1}{1-s}+1-\mu\right) \frac{c_{t}}{\lambda b x_{t}}+\frac{\mu-1}{b x_{t}}-\rho\right]
$$

where we have used the fact that $\dot{X}_{t} / X_{t}=\mu \iota_{t}$. When $\mu<1+\frac{\lambda-1}{1-s}$, the expression in the inner parentheses in Eq. B.2 is positive and $\dot{c}_{t}=0$ is an upward-sloping curve (case a). Conversely, when $\mu>1+\frac{\lambda-1}{1-s}$, the expression in the inner parentheses in Eq. (B.2) is negative and $\dot{c}_{t}=0$ defines a downward-sloping curve (case b). In both cases, starting from any point on this curve, an increase in $x_{t}$ leads to $\dot{c}_{t}<0$ and a decrease in $x_{t}$ leads to $\dot{c}_{t}>0$. As shown in Figure 1, regardless of whether $\dot{c}_{t}=0$ is an upward- or downward-sloping curve, there exists an upward-sloping saddle path going through the unique balanced growth equilibrium point A. Thus, we conclude that the balanced growth equilibrium is saddlepath stable. 


\section{References}

Aghion, P., Akcigit, U., and Howitt, P. (2013a). "What do we learn from schumpeterian growth theory?" Working Paper 18824, National Bureau of Economic Research.

Aghion, P., Farhi, E., and Kharroubi, E. (2012). "Monetary policy, liquidity, and growth". Working Paper 18072, National Bureau of Economic Research.

Aghion, P. and Howitt, P. (1992). "A model of growth through creative destruction". Econometrica, 60(2):323351.

Aghion, P. and Howitt, P. (2008). Endogenous Growth Theory. Cambridge, MA: MIT Press.

Aghion, P., Howitt, P., and Prantl, S. (2013b). "Patent rights, product market reforms, and innovation". Working Paper 18854, National Bureau of Economic Research.

Alonso-Borrego, C., Galán-Zazo, J. I., Forcadell, F. J., and Ángel Zúñiga Vicente, J. (2014). "Assessing the effect of public subsidies on firm R\&D investment: a survey". Journal of Economic Surveys, 28(1):36?67.

Ang, J. B. (2011). "Financial development, liberalization and technological deepening". European Economic Review, 55(5):688-701.

Ang, J. B. and Madsen, J. B. (2011). "Can second-generation endogenous growth models explain the productivity trends and knowledge production in the Asian miracle economies?" The Review of Economics and Statistics, 93(4):1360-1373.

Arnold, J. M., Brys, B., Heady, C., Johansson, Å., Schwellnus, C., and Vartia, L. (2011). "Tax policy for economic recovery and growth". The Economic Journal, 121(550):F59-F80.

Atkeson, A. and Burstein, A. T. (2011). "Aggregate implications of innovation policy". Working Paper 17493, National Bureau of Economic Research.

Barro, R. J. (1990). "Government spending in a simple model of endogenous growth". Journal of Political Economy, 98(5):S103-26.

BEA (2008). "BEA GDP by industry components, historical series, 1997-2000". Technical report, US Bureau of Economic Analysis.

Becker, R. A. and Gray, W. B. (2009). "NBER-CES manufacturing industry database". Technical report, NBER.

Bergh, A. and Henrekson, M. (2011). "Government size and growth: A survey and interpretation of the evidence". Journal of Economic Surveys, 25(5):872-897.

Bloom, N., Griffith, R., and Van Reenen, J. (2002). "Do R\&D tax credits work? evidence from a panel of countries 1979-1997". Journal of Public Economics, 85(1):1-31.

Bloom, N., Schankerman, M., and Van Reenen, J. (2013). "Identifying technology spillovers and product market rivalry". Econometrica, Forthcoming. 
Bottazzi, L. and Peri, G. (2007). "The international dynamics of R\&D and innovation in the long run and in the short run". Economic Journal, 117(518):486-511.

Busom, I., Corchuelo, B., and Martinez Ros, E. (2012). "Tax incentives or subsidies for R\&D?" Technical report.

Coe, D. T. and Helpman, E. (1995). "International R\&D spillovers". European Economic Review, 39(5):859 887.

Conway, P. and Nicoletti, G. (2006). "Product market regulation in the non-manufacturing sectors of OECD countries: Measurement and highlights". OECD Economics Department Working Papers 530, OECD Publishing.

Corrado, C., Hulten, C., and Sichel, D. (2005). "Measuring capital and technology: An expanded framework". In "Measuring Capital in the New Economy", NBER Chapters, pages 11-46. National Bureau of Economic Research, Inc.

Crepon, B., Duguet, E., and Mairessec, J. (1998). "Research, innovation and productivity: An econometric analysis at the firm level". Economics of Innovation and New Technology, 7(2):115-158.

Şener, F. (2001). "Schumpeterian unemployment, trade and wages". Journal of International Economics, 54(1):119-148.

Czarnitzki, D. and Toivanen, O. (2013). "Innovation policy and economic growth". European Economy - Economic Papers 482, Directorate General Economic and Monetary Affairs (DG ECFIN), European Commission.

David, P. A., Hall, B. H., and Toole, A. A. (2000). "Is public R\&D a complement or substitute for private R\&D? A review of the econometric evidence". Research Policy, 29(4-5):497-529.

Dinopoulos, E. and Segerstrom, P. (1999). "A Schumpeterian model of protection and relative wages". American Economic Review, 89(3):450-472.

Dinopoulos, E. and Syropoulos, C. (2007). "Rent protection as a barrier to innovation and growth". Econ Theory, 32(2):309-332.

Dinopoulos, E. and Thompson, P. (1996). "A contribution to the empirics of endogenous growth". Eastern Economic Journal, 22(4):389-400.

Dinopoulos, E. and Thompson, P. (1998). "Schumpeterian growth without scale effects". J Econ Growth, 3(4):313335.

Easterly, W. and Rebelo, S. (1993). "Fiscal policy and economic growth: An empirical investigation". Journal of Monetary Economics, 32(3):417-458.

Eberhardt, M. and Bond, S. (2009). "Cross-section dependence in nonstationary panel models: a novel estimator". MPRA Paper 17692, University Library of Munich, Germany.

Ertur, C. and Koch, W. (2011). "A contribution to the theory and empirics of Schumpeterian growth with worldwide interactions". Journal of Economic Growth, 16(3):215-255. 
Feenstra, R. C. and Kee, H. L. (2007). "Trade liberalisation and export variety: A comparison of Mexico and China". The World Economy, 30(1):5-21.

Feenstra, R. C., Romalis, J., and Schott, P. K. (2002). "U.S. imports, exports, and tariff data, 1989-2001". NBER Working Papers 9387, National Bureau of Economic Research, Inc.

Franco, C., Pieri, F., and Venturini, F. (2013). "Product market regulation and innovation efficiency". Working Papers 1313, Department of Applied Economics II, Universidad de Valencia.

Frensch, R. and Gaucaite Wittich, V. (2009). "Product variety and technical change". Journal of Development Economics, 88(2):242-257.

Gemmell, N., Kneller, R., and Sanz, I. (2011). "The timing and persistence of fiscal policy impacts on growth: Evidence from OECD countries". Economic Journal, 121(550):F33-F58.

Gemmell, N., Kneller, R., and Sanz, I. (2013). "The growth effects of tax rates in the OECD". Technical report.

Goolsbee, A. (1998). "Does government r\&d policy mainly benefit scientists and engineers?" American Economic Review, 88(2):298-302.

Grossman, G. M. and Helpman, E. (1991). "Quality ladders in the theory of growth". Review of Economic Studies, 58(1):43-61.

Grossman, G. M. and Helpman, E. (1993). Innovation and Growth in the Global Economy, volume 1 of MIT Press Books. The MIT Press.

Guellec, D. and Van Pottelsberghe, B. (2003). "The impact of public R\&D expenditure on business R\&D". Economics of Innovation and New Technology, 12(3):225-243.

Guellec, D. and Van Pottelsberghe De La Potterie, B. (2003). "The impact of public R\&D expenditure on business R\&D". Economics of Innovation and New Technology, 12(3):225-243.

Ha, J. and Howitt, P. (2007). "Accounting for trends in productivity and R\&D: A Schumpeterian critique of semi-endogenous growth theory". Journal of Money, Credit and Banking, 39(4):733-774.

Hall, B. H. (1993). "R\&D tax policy during the 1980s: Success or failure?" In "Tax Policy and the Economy, Volume 7", NBER Chapters, pages 1-36. National Bureau of Economic Research, Inc.

Hall, B. H., Jaffe, A. B., and Trajtenberg, M. (2001). "The NBER patent citation data file: Lessons, insights and methodological tools". Working Paper 8498, National Bureau of Economic Research.

Hall, R. E. and Jorgenson, D. W. (1967). "Tax policy and investment behavior". The American Economic Review, 57:391-414.

Harberger, A. (1964). "Taxation, resource allocation, and welfare". In "The Role of Direct and Indirect Taxes in the Federal Reserve System", NBER Chapters, pages 25-80. National Bureau of Economic Research, Inc.

Impullitti, G. (2010). "International competition and u.s. r\&d subsidies: A quantitative welfare analysis". International Economic Review, 51(4):1127-1158. 
Jones, C. and Williams, J. (2000). "Too much of a good thing? the economics of investment in R\&D". Journal of Economic Growth, 5(1):65-85.

Jones, C. I. (1995a). "R\&D-based models of economic growth". Journal of Political Economy, 103(4):759-784.

Jones, C. I. (1995b). "Time series tests of endogenous growth models". The Quarterly Journal of Economics, 110(2):495-525.

Jones, L. E. and Manuelli, R. E. (2005). "Neoclassical models of endogenous growth: The effects of fiscal policy, innovation and fluctuations". In P. Aghion and S. Durlauf, editors, "Handbook of Economic Growth", volume 1 of Handbook of Economic Growth, chapter 1, pages 13-65. Elsevier.

Jones, L. E., Manuelli, R. E., and Rossi, P. E. (1993). "Optimal taxation in models of endogenous growth". Journal of Political Economy, 101(3):485-517.

King, R. G. and Rebelo, S. (1990). "Public policy and economic growth: Developing neoclassical implications". Journal of Political Economy, 98(5):S126-50.

KLEMS, E. (2008). "EU KLEMS growth and productivity accounts: March 2008 release". Technical report, EU KLEMS.

Klette, T. J., Moen, J., and Griliches, Z. (2000). "Do subsidies to commercial R\&D reduce market failures? microeconometric evaluation studies1". Research Policy, 29(4-5):471-495.

Kneller, R., Bleaney, M. F., and Gemmell, N. (1999). "Fiscal policy and growth: evidence from OECD countries". Journal of Public Economics, 74(2):171-190.

Kortum, S. S. (1997). "Research, patenting, and technological change". Econometrica, 65(6):pp. 1389-1419.

Levin, R. and Reiss, P. C. (1984). "Tests of a Schumpeterian model of R\&D and market structure". In "R \& D, Patents, and Productivity", NBER Chapters, pages 175-208. National Bureau of Economic Research, Inc.

Leyden, D. P. and Link, A. N. (1991). "Why are governmental R\&D and private R\&D complements?" Applied Economics, 23(10):1673-1681.

Lichtenberg, F. R. (1984). "The relationship between federal contract R\&D and company R\&D". The American Economic Review, 74(2):pp. 73-78.

Lichtenberg, F. R. (1987). "The effect of government funding on private industrial research and development: A re-assessment". The Journal of Industrial Economics, 36(1):pp. 97-104.

Lichtenberg, F. R. (1988). "The private R\&D investment response to federal design and technical competitions". American Economic Review, 78(3):550-59.

Lokshin, B. and Mohnen, P. (2013). "Do r\&d tax incentives lead to higher wages for r\&d workers? evidence from the netherlands". Research Policy, 42(3):823-830.

Madsen, J. (2008). "Semi-endogenous versus Schumpeterian growth models: testing the knowledge production function using international data". Journal of Economic Growth, 13(1):1-26. 
Madsen, J., Ang, J., and Banerjee, R. (2010a). "Four centuries of british economic growth: the roles of technology and population". Journal of Economic Growth, 15(4):263-290.

Madsen, J. B. (2007). “Are there diminishing returns to R\&D?" Economics Letters, 95(2):161-166.

Madsen, J. B. (2010). "The anatomy of growth in the OECD since 1870". Journal of Monetary Economics, 57(6):753-767.

Madsen, J. B., Islam, M. R., and Ang, J. B. (2010b). "Catching up to the technology frontier: the dichotomy between innovation and imitation". Canadian Journal of Economics, 43(4):1389-1411.

Madsen, J. B., Saxena, S., and Ang, J. B. (2010c). "The Indian growth miracle and endogenous growth". Journal of Development Economics, 93(1):37-48.

Mamuneas, T. P. and Nadiri, M. (1996). "Public R\&D policies and cost behavior of the US manufacturing industries". Journal of Public Economics, 63(1):57-81.

Mansfield, E. (1986). "The R\&D tax credit and other technology policy issues". American Economic Review, 76(2):190-94.

Mendoza, E. G., Milesi-Ferretti, G. M., and Asea, P. (1997). "On the ineffectiveness of tax policy in altering long-run growth: Harberger's superneutrality conjecture". Journal of Public Economics, 66(1):99-126.

Mohnen, P. and Lokshin, B. (2009). "What does it take for an R\&D tax incentive policy to be effective?" Technical report.

Nickell, S. J. (1981). "Biases in dynamic models with fixed effects". Econometrica, 49(6):1417-26.

Peretto, P. F. (1998). "Technological change and population growth". Journal of Economic Growth, 3(4):283-311.

Peretto, P. F. (2003). "Fiscal policy and long-run growth in R\&D-based models with endogenous market structure". Journal of Economic Growth, 8(3):325-47.

Peretto, P. F. (2007). "Corporate taxes, growth and welfare in a Schumpeterian economy". Journal of Economic Theory, 137(1):353-382.

Pesaran, H. M., Shin, Y., and Smith, R. P. (1999). "Pooled mean group estimation of dynamic heterogeneous panels". Journal of the American Statistical Association, 94:621?-634.

Pesaran, M. H. (2006). "Estimation and inference in large heterogeneous panels with a multifactor error structure". Econometrica, 74(4):967-1012.

Pesaran, M. H. and Smith, R. (1995). "Estimating long-run relationships from dynamic heterogeneous panels". Journal of Econometrics, 68(1):79-113.

Romer, P. M. (1990). "Endogenous technological change". Journal of Political Economy, 98(5):S71-102.

Scott, J. (1984). "Firm versus industry variability in R\&D intensity". In "R \& D, Patents, and Productivity", NBER Chapters, pages 233-248. National Bureau of Economic Research, Inc. 
Segerstrom, P. S. (1998). "Endogenous growth without scale effects". American Economic Review, 88(5):12901310.

Segerstrom, P. S. (2000). "The long-run growth effects of R\&D subsidies". Journal of Economic Growth, 5(3):277305.

Thomson, R. (2013). "The effectiveness of R\&D tax credits: Cross-industry evidence". Melbourne Institute Working Paper Series wp2013n18, Melbourne Institute of Applied Economic and Social Research, The University of Melbourne.

Ulku, H. (2007). "R\&D, innovation, and growth: evidence from four manufacturing sectors in OECD countries". Oxford Economic Papers, 59(3):513-535.

Venturini, F. (2012a). "Looking into the black box of Schumpeterian growth theories: An empirical assessment of R\&D races". European Economic Review, 56(8):1530-1545.

Venturini, F. (2012b). "Product variety, product quality, and evidence of endogenous growth". Economics Letters, $117(1): 74-77$.

Von Furstenberg, G. and Von Kalckreuth, U. (2006). "Dependence on external finance: An inherent industry characteristic?" Open Economies Review, 17(4):541-559.

Westmore, B. (2013). "Innovation and growth: Considerations for public policy". Review of Economics and Institutions, $4(3)$.

Wilson, D. J. (2009). "Beggar thy neighbor? the in-state, out-of-state, and aggregate effects of R\&D tax credits". The Review of Economics and Statistics, 91(2):431-436.

Young, A. (1998). "Growth without scale effects". Journal of Political Economy, 106(1):pp. 41-63.

Zachariadis, M. (2003). "R\&D, innovation, and technological progress: a test of the Schumpeterian framework without scale effects". Canadian Journal of Economics, 36(3):566-586.

Zachariadis, M. (2004). "R\&D-induced growth in the OECD?" Review of Development Economics, 8(3):423-439. 


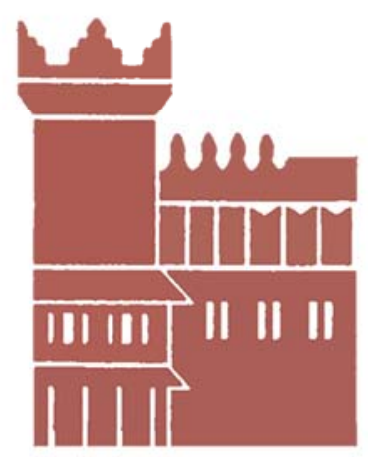

Alma Mater Studiorum - Università di Bologna DEPARTMENT OF ECONOMICS

Strada Maggiore 45

40125 Bologna - Italy

Tel. +39051 2092604

Fax +390512092664

http://www.dse.unibo.it 